\title{
The roles of osteocytes in alveolar bone destruction in periodontitis
}

\author{
Xiaofei Huang ${ }^{1,2}$, Mengru Xie ${ }^{1,2}$, Yanling Xie ${ }^{1,2}$, Feng Mei ${ }^{1,2}$, Xiaofeng Lu ${ }^{1,2}$, Xiaoshuang $\mathrm{Li}^{1,2^{*}}$ and Lili Chen ${ }^{1,2^{*}}$
}

\begin{abstract}
Periodontitis, a bacterium-induced inflammatory disease that is characterized by alveolar bone loss, is highly prevalent worldwide. Elucidating the underlying mechanisms of alveolar bone loss in periodontitis is crucial for understanding its pathogenesis. Classically, bone cells, such as osteoclasts, osteoblasts and bone marrow stromal cells, are thought to dominate the development of bone destruction in periodontitis. Recently, osteocytes, the cells embedded in the mineral matrix, have gained attention. This review demonstrates the key contributing role of osteocytes in periodontitis, especially in alveolar bone loss. Osteocytes not only initiate physiological bone remodeling but also assist in inflammation-related changes in bone remodeling. The latest evidence suggests that osteocytes are involved in regulating bone anabolism and catabolism in the progression of periodontitis. The altered secretion of receptor activator of NF-KB ligand (RANKL), sclerostin and Dickkopf-related protein 1 (DKK1) by osteocytes affects the balance of bone resorption and formation and promotes bone loss. In addition, the accumulation of prematurely senescent and apoptotic osteocytes observed in alveolar bone may exacerbate local destruction. Based on their communication with the bloodstream, it is noteworthy that osteocytes may participate in the interaction between local periodontitis lesions and systemic diseases. Overall, further investigations of osteocytes may provide vital insights that improve our understanding of the pathophysiology of periodontitis.
\end{abstract}

Keywords: Osteocyte, Periodontitis, RANKL, Sclerostin, Senescence, Apoptosis

\section{Introduction}

Periodontitis is a complicated, multifaceted process that results in the disorganization of the underlying ligament and alveolar bone. Studies on the mechanisms of periodontitis have always focused on alveolar bone loss, especially the function of osteoclasts and osteoblasts in this process. However, the past few years have witnessed a substantial increase in our understanding of the capacities of osteocytes, and the notion that they are in a state of inactivity has been rejected. An increasing number of studies have revealed a key role of osteocytes in physiological and pathological skeletal events, including

\footnotetext{
*Correspondence: lixiaoshuang0220@163.com; chenlili1030@hust.edu.cn

${ }^{+}$Xiaofei Huang and Mengru Xie contributed equally to this work

1 Department of Stomatology, Union Hospital, Tongji Medical College, Huazhong University of Science and Technology, Wuhan 430022, China

Full list of author information is available at the end of the article
}

periodontitis. The intention of this review is to summarize the role of osteocytes in the remodeling of alveolar bone in periodontitis on the basis of existing evidence in order to provide new insights for future studies of the mechanisms underlying alveolar bone loss in periodontitis and the clinical treatment of periodontitis.

\section{Periodontitis and alveolar bone loss}

Periodontitis has become the most common and consequential oral disease and is among the most important clinical conditions that have attracted considerable attention in the public health field [1]. From 1990 to 2010, the prevalence of severe periodontitis in the entire population remained stable at $11.2 \%$ [2]. Periodontitis is characterized by the progressive breakdown of supportive periodontal tissues, especially the loss of alveolar bone. As lesions develop, the height of the alveolar bone

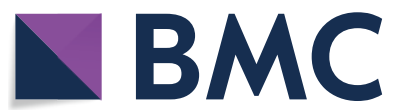

(c) The Author(s) 2020. This article is licensed under a Creative Commons Attribution 4.0 International License, which permits use, sharing, adaptation, distribution and reproduction in any medium or format, as long as you give appropriate credit to the original author(s) and the source, provide a link to the Creative Commons licence, and indicate if changes were made. The images or other third party material in this article are included in the article's Creative Commons licence, unless indicated otherwise in a credit line to the material. If material is not included in the article's Creative Commons licence and your intended use is not permitted by statutory regulation or exceeds the permitted use, you will need to obtain permission directly from the copyright holder. To view a copy of this licence, visit http://creativecommons.org/licenses/by/4.0/. The Creative Commons Public Domain Dedication waiver (http://creativecommons.org/publicdomain/zero/1.0/) applies to the data made available in this article, unless otherwise stated in a credit line to the data. 
gradually decreases, and the tooth foundation becomes weak, resulting in exposed tooth roots and loosened teeth, which, if left untreated, eventually result in tooth loss. This condition severely damages chewing efficiency, nutrition intake, aesthetics and mental health and has an adverse effect on people's lives. Furthermore, periodontitis is closely related to multiple systemic diseases, such as atherosclerosis [3], diabetes mellitus (DM) [4], rheumatoid arthritis (RA) [5] and osteoporosis [6], and some patients with these conditions were reported to present more severe bone loss.

Alveolar bone is a dynamic and vibrant tissue. Normally, alveolar bone is subjected to mechanical stimulation and undergoes a continuous cycle of remodeling that is mainly based on the coordinated activities of two pivotal cell types: cells of the osteoblast lineage, including osteoblasts, osteocytes, and bone-lining cells, and boneresorbing cells, such as osteoclasts. When osteoclasts are activated, they attach to the bone surface and produce protons $\left(\mathrm{H}^{+}\right)$and proteases to degrade the bone mineral matrix; thereafter, osteoblasts synthesize osteoid matrix and regulate the mineralization process. Under the regulation of various hormones and cytokines, bone resorption and bone formation are connected and balanced so that new bone can replace old bone, stabilizing the volume of alveolar bone [7]. However, in periodontitis, this balance is disrupted. Periodontal pathogen virulence overwhelms the oral mucosal defensive barrier and forces the epithelium to retreat apically on the root surface, resulting in the formation of a periodontal pocket. Resident cells, such as fibroblasts, keratinocytes and dendritic cells, within the tissue release inflammatory cytokines, which promote multiple inflammatory cells, such as neutrophils, macrophages, and T/B cells $[8,9]$, to migrate to the site of inflammation and gradually infiltrate deeper into the periodontal connective tissue, including alveolar bone. These inflammatory cells produce antimicrobial agents, reactive oxygen species, and enzymes to eliminate pathogens but also disrupt the normal activity of alveolar bone remodeling $[10,11]$. Osteoclasts are induced and activated, while osteoblasts are inhibited, which disrupts the balance between bone removal and regeneration, leading to a reduction in bone volume [12].

Studies on the mechanism of bone loss in periodontitis have emphasized the role of osteoclasts and osteoblasts. However, some questions remain, such as what initiates bone remodeling in periodontitis, what directs osteoclast and osteoblast formation and localization, and how periodontitis interacts with systemic diseases. With the emergence of additional attention and studies on osteocytes, we have realized that there are some omissions and inaccuracies in our previous understanding. Abnormal osteocytes can lead to bone loss (Table 1). For example, targeted osteocyte ablation led to severe bone resorption and a fragile and sparse bone phenotype [13]. Adultonset deletion of $\beta$-catenin from osteocytes can impact loading-induced bone adaptive reconstruction, contributing to decreased bone mass and density in mice [14]. Selective deletion of Tnfsf11 (the gene encoding RANKL) in osteocytes resulted in a severe osteopetrotic phenotype [15]. Knock out of colony-stimulating factor (CSF)-1 in osteocytes increased osteocyte apoptosis due to the overproduction of intracellular reactive oxygen species and ultimately compromised bone formation and resorption, leading to increased cancellous bone [16]. Osteocyte-specific knockout of Wnt1 caused low bone mass in mice, similar to that observed in osteogenesis imperfecta, because of a subsequent reduction in mammalian target of rapamycin complex 1 (mTORC1)-dependent osteoblast function [17]. These data suggested that the role of osteocytes in bone loss may extend beyond our current understanding. We should pay more attention to the functions of osteocytes, and this may provide new insights into the pathological processes underlying bone destruction in periodontitis.

\section{Osteocytes and their function}

Osteocytes are one cell type that results from the terminal differentiation of osteoblasts and are the most numerous and long-lived cells in the bone. Osteocytes always occupy the lacunar space that is full of bone fluid, and osteocytes are characterized by an additional

Table 1 Specific gene deletion evidences on the role of osteocytes in bone resorption

\begin{tabular}{lllll}
\hline Gene & $\begin{array}{l}\text { Gene-editing } \\
\text { method }\end{array}$ & Signaling pathway & Bone phenotype(s) & References \\
\hline$\beta$-catenin & Deletion & Wnt/ $\beta$-catenin signaling & Bone resorption $\uparrow$, bone mass and density $\downarrow$ & {$[14]$} \\
Tnfsf11 & Deletion & RANKL/RANK/OPG system & Bone resorption $\downarrow$ & {$[15]$} \\
Csf-1 & Deletion & CSF-1/Nox4/oxidative stress & Bone formation $\downarrow$, bone resorption $\downarrow$ & {$[16]$} \\
$W n t 1$ & Deletion & Wnt1-mTOR signaling & Bone formation $\downarrow$ & {$[17]$} \\
Pgc-1 & Deletion & AMPK/PGC-1 pathway & Bone volume $\downarrow$ & {$[24]$} \\
\hline
\end{tabular}


50-60 cellular processes radiating from the cell body and extending through confined passages of canaliculi, all buried in the bone mineral matrix, which is also called the lacuno-canalicular system (LCS) [18]. Osteocytes interconnect cells, including each other and those over the bone surface, through dendritic processes coupled with gap junctions, which form the cellular functional network within the bone [19]. Osteocytes are versatile. Osteocytes act as orchestrators of bone remodeling in response to mechanical loading [20], changes in hormone levels [21], or other stimuli. A high prevalence of apoptosis in osteocytes induced by bone uploading was found to increase the expression of the osteocytic factor receptor activator of NF- $\mathrm{KB}$ ligand (RANKL), which exacerbated bone resorption in response to skeletal unloading [22]. Downregulation of sclerostin in osteocytes in response to parathyroid hormone $(\mathrm{PTH})$ promotes osteoblastic activity and bone formation [23]. The AMP-activated protein kinase (AMPK)/proliferator-activated receptor co-activator-1 (PGC-1) pathway mediates low glucose-induced osteocytic gene expression, and conditional deletion of PGC-1 in osteocytes reduced the expression of osteocyte genes, such as dentin matrix protein (Dmp1), fibroblast growth factor 23 ( Fgf23) and Sost, and consequently resulted in osteopenic phenomena [24].

Evidence has shown crosstalk among osteocytes, osteoclasts and osteoblasts and indicates that this crosstalk is required for physiological osseous turnover and homeostasis maintenance. On the one hand, osteocytes can affect osteoclasts. Osteocytes are the primary sources of RANKL, which acts upon receptor activator of NF- $\kappa B$ (RANK) and controls the differentiation of osteoclasts. RANKL expression is ten times higher in osteocytes than in osteoblasts and much higher in osteocytes than in other mesenchymal cells $[15,25]$. Osteocytes can also predominantly produce osteoprotegerin (OPG), which prevents RANKL from activating osteoclastogenesis. Animate osteocytes can positively direct osteoclast formation and bone resorption by upregulating RANKL and downregulating OPG or, inversely, promote the opposite conditions to reduce bone resorption [26]. Additionally, dying osteocytes can control bone resorption. Osteocytes often undergo apoptosis in the context of bone microdamage, which is a principal trigger of site-specific resorption. For example, in osteocyte-specific connexin 43-knockout mice, increased osteocyte apoptosis and a lack of osteogenic and osteoclastic regulators, such as OPG and sclerostin, were observed, and these conditions increased endocortical resorption and periosteal bone formation [27]. On the other hand, osteocytes can affect osteoblasts in a stimulatory or inhibitory manner. Sclerostin and Dickkopf-related protein 1 (DKK1) are among the most potent signals originating from osteocytes.
These molecules act as strong antagonists of $\mathrm{Wnt} / \beta$ catenin signaling, which is an important pathway for promoting osteoblastogenesis and matrix formation [28, 29] (Fig. 1). Below, the recently elucidated role of osteocytes in the pathogenesis of periodontitis is discussed, highlighting RANKL and sclerostin secretion, osteocyte senescence, osteocyte apoptosis, and their potential effect on the association of periodontitis with systemic disease.

\section{The altered secretory function of osteocytes in periodontitis \\ Osteocytes upregulate the expression of RANKL in periodontitis}

Periodontitis tissue is flooded with many pathological factors, including biologically active substances within bacterial plaques and inflammatory mediators released by immune cells. Lipopolysaccharide (LPS) from gram-negative bacteria, which is recognized by Toll-like receptors (TLRs), such as TLR2, on the osteocyte surface irritates the downstream mitogen-activated protein kinase (MAPK)/extracellular signal-regulated kinase (ERK)1/2 signaling pathway and transcription factors, leading to upregulation of interleukin (IL)-6 expression [30]. IL-6 triggers gp130-mediated Janus kinase (JAK) activation, which then phosphorylates signal transducer and activator of transcription (STAT) [31]. Activated STAT translocates into the nucleus and ultimately increases RANKL expression in osteocytes [31, 32]. Inflammatory molecules from the host immune response, such as tumor necrosis factor- $\alpha$ (TNF- $\alpha$ ) and IL- $1 \beta$, are also conducive to increasing RANKL expression in osteocytes [33]. By binding to the TNF receptor on the osteocyte surface, TNF- $\alpha$ activates the ERK1/2, P38 and Jun kinase (JNK) MAPK signaling pathways and/or the transcription factor nuclear factor-kappa B (NF-kB), which enhances RANKL expression in osteocytes and consequently promotes alveolar bone resorption [34, 35] (Fig. 2). Many years ago, researchers discovered significantly enhanced RANKL content, along with downregulated OPG levels, in alveolar bone in periodontitis [36]. As the RANKL/ OPG ratio increases, the quantity of osteoclasts increases accordingly, and the bone resorption area expands [37]. For a long time, we thought that $\mathrm{T} / \mathrm{B}$ cells were the primary sources of RANKL in periodontitis [38, 39]. However, recent evidence has proven that osteocytes produce a large proportion of RANKL during bone remodeling in periodontitis $[15,40]$. Induction of periodontitis stimulated a seven-fold increase in RANKL expression in murine osteocytes, consistent with the increased osteoclast number and bone resorption [35]. Through the utilization of transgenic model mice, scholars have observed 


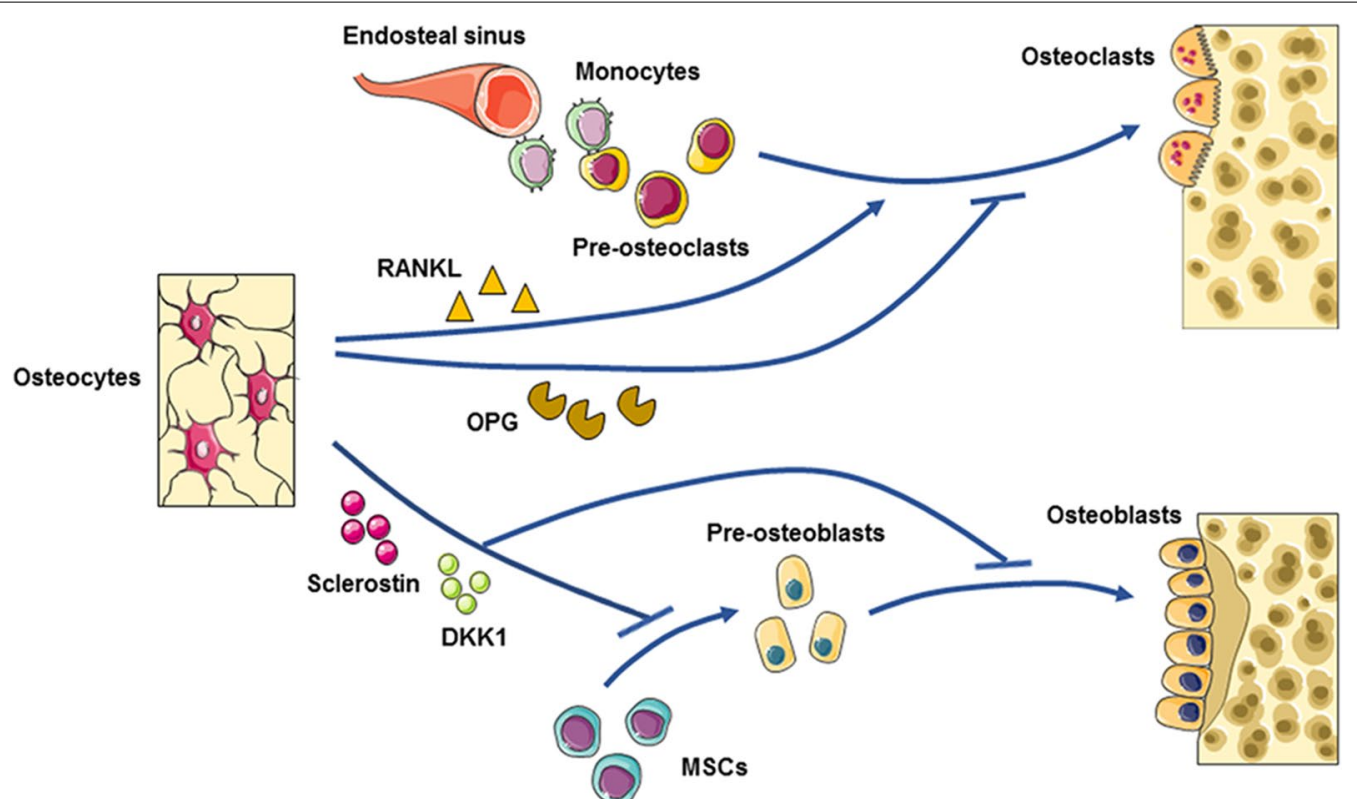

Fig. 1 Osteocytes initiate bone remodeling through the regulation of osteoclasts and osteoblasts. (Top) Osteocytes express RANKL to promote, and OPG to inhibit, osteoclast generation and bone resorption. (Bottom) Osteocytes also secrete sclerostin and DKK1 to inhibit osteoblast formation and activity

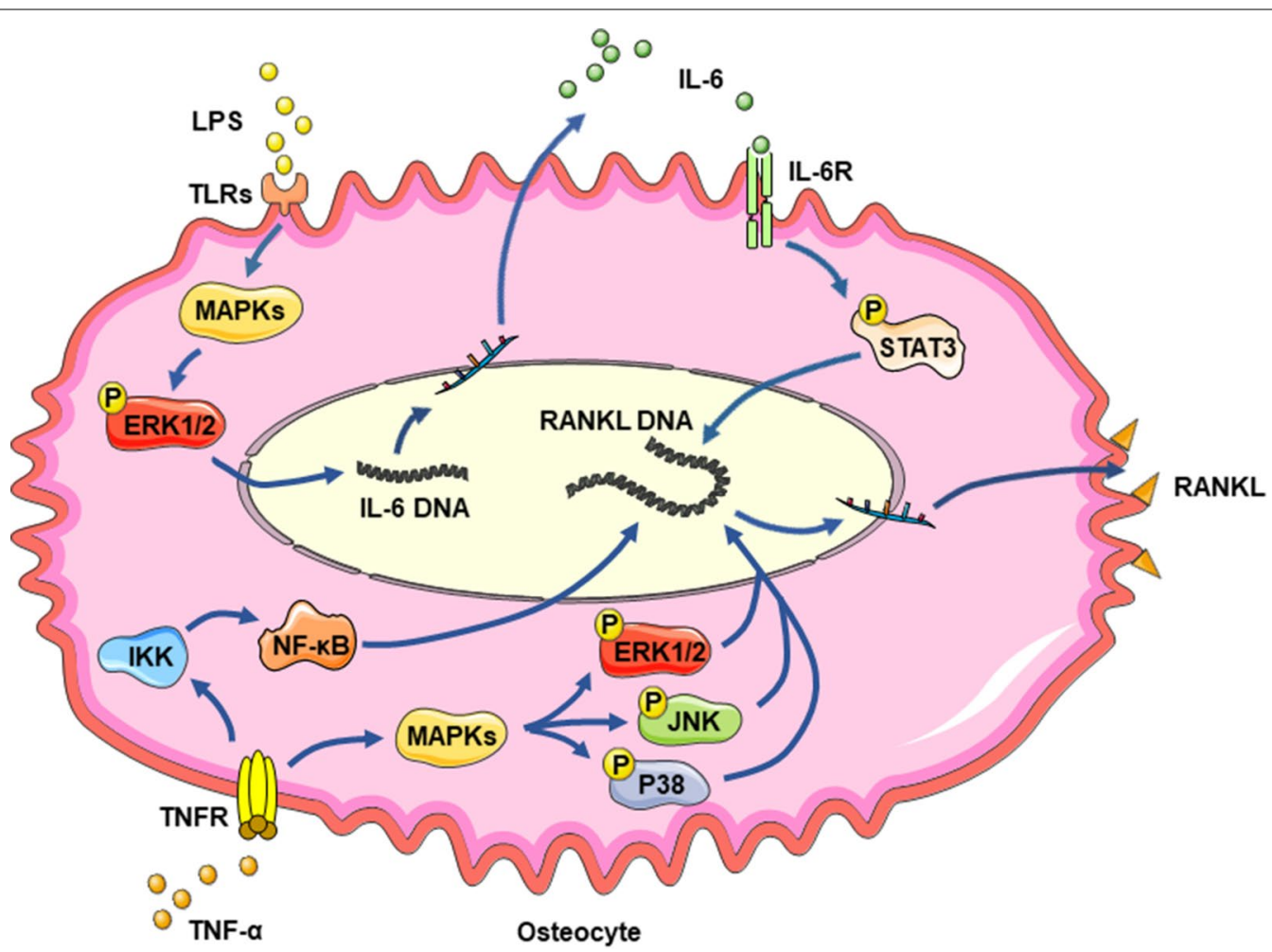

Fig. 2 RANKL expression in osteocytes is upregulated under LPS and TNF-a stimulation. LPS binds to TLRs and activates the MAPK/ERK1/2 pathway, which promotes IL-6 production in osteocytes. IL-6 subsequently enhances RANKL expression by facilitating STAT signal transduction. TNF-a can promote RANKL generation through the NF-KB pathway and the ERK1/2, JNK and P38 MAPK pathways 
the unique activity of osteocyte-produced RANKL in periodontitis bone resorption [8].

RANKL is a TNF superfamily protein. RANKL serves as a key regulator of osteoclastogenesis and functions as a membrane-bound or soluble form. The combination of RANKL and RANK on the cytomembrane of osteoclast precursors and osteoclasts is required for osteoclast fusion, differentiation, activation and subsistence [37], and the membrane-binding form of RANKL serves in a dominant way [41]. It has long been recognized that the content of RANKL is strongly related to the severity of bone resorption. OPG, which is mainly expressed by cells of the osteoblast lineage, is a soluble decoy receptor of RANKL. OPG competes with RANK to inhibit RANKL/ RANK binding to restrain the activation of osteoclasts [26, 37].

Membrane-bound RANKL is essential for bone resorption. Because osteocytes are embedded deep in the hard bone matrix, how RANKL on the osteocyte surface interacts with preosteoclasts located on the bone surface is unknown the answer to this question involves the subcellular transport of RANKL. The use of a combination of a collagen-embedded 3D culture system and a porous membrane separating osteocytes from bone marrow macrophages (BMMs) of C57BL/6 J mice facilitated the investigation of the regulatory mechanism of RANKL transport in osteocytes under the premise of maintaining the physiological morphology of bone cells [41]. It was concluded that osteocytes directly interact with BMMs via the extremities of their dendritic processes and provide the latter with RANKL, which was promoted upon stimulation with RANK-conjugated beads. Furthermore, RANKL is mainly concentrated in osteocyte lysosomes, and OPG is required for regulation of RANKL trafficking [41].

At present, drugs designed to inhibit RANKL in order to inhibit osteoclast activity and prevent bone resorption have been developed. Denosumab, an anti-RANKL monoclonal antibody, is currently being used to treat patients with osteoporosis at high risk of hip fracture and the progression and metastasis of cancer and giant cell tumors within bone [42]. However, these drugs are still in preclinical trials for treatment of periodontitis. In some studies, the application of a monoclonal antibody specific for RANKL was demonstrated to be effective in ameliorating alveolar bone destruction in experimental periodontitis and LPS-induced calvarial bone damage in a mouse model; the coverage of osteoclasts in calvaria was greatly diminished, and the amount of resorption pits caused by osteoclasts was significantly reduced compared to that in the control group [43]. The same therapeutic outcome was shown in a mouse model of periodontitis treated with a human recombinant OPG fusion protein [44]. However, traditional anti-resorption drugs can cause serious complications, such as osteonecrosis of the jaw (ONJ) and atypical femoral fractures [45]. Due to suppressed osteoclast function, bone turnover is reduced, resulting in diminished mineral density and serum calcium $[46,47]$. Jaw bones are susceptible to adverse drug reactions because they are subjected to constant mechanical stress, undergo frequent remodeling and have relatively high vascularity, which may partly explain the specific location of ONJ [48]. These side effects limit the use of anti-resorption medication in the treatment of periodontal disease. Therefore, more research is needed to improve the application of antiRANKL therapy in periodontitis to lower alveolar bone loss.

\section{Osteocytes generate more sclerostin and DKK1 in periodontitis}

The mechanism of bone loss in periodontitis involves not only the enhancement of osteoclast activity but also the weakening of osteoblast activity, which exacerbates the progressive destruction of alveolar bone. Proinflammatory cytokines, such as TNF- $\alpha$ and IL- $1 \beta$, can induce sclerostin expression in osteocytes. TNF- $\alpha$ can enhance sclerostin expression through an NF- $\mathrm{kB}$-dependent mechanism, during which NF- $\mathrm{kB}$ directly binds to the $S O S T$ promoter region and induces an increase in sclerostin expression [35, 49] (Fig. 3). DKK1 can enhance the sclerostin expression induced by TNF- $\alpha$ in osteocytes to inhibit osteoblast activity and impair bone formation [50]. Evidence related to the effects of periodontitis bacteria and their toxic substances on sclerostin production

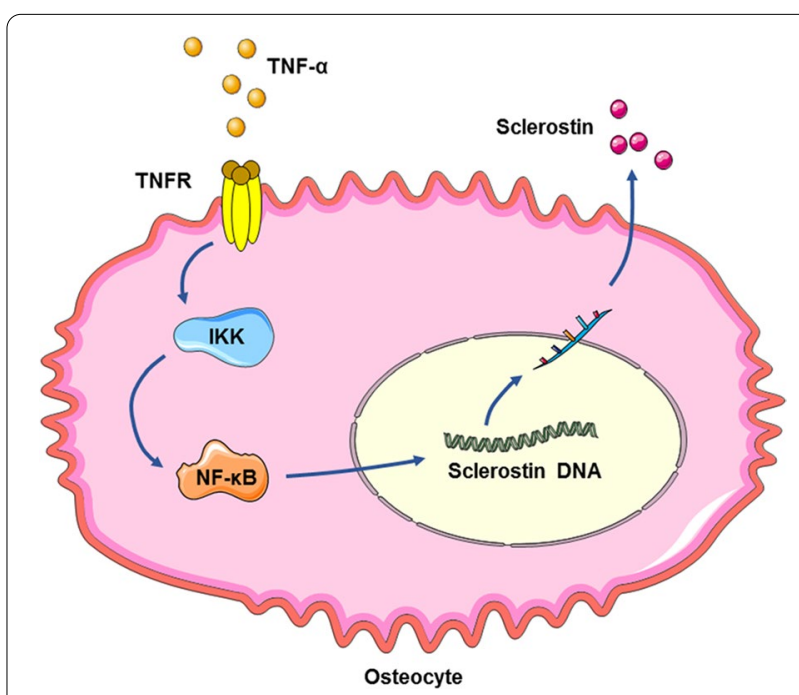

Fig. 3 TNF-a mediates sclerostin expression in osteocytes via the NF-kB pathway 
in osteocytes is insufficient. LPS may indirectly promote sclerostin production by stimulating osteocytes to produce TNF- $\alpha$, IL- 6 and other pro-inflammatory factors, but no evidence has been found to show its direct effect [51].

The sclerostin content in gingival crevicular fluid from chronic periodontitis patients markedly exceeds that of healthy subjects [52], and the protein levels of sclerostin and DKK1 in gingival biopsy tissue and serum are relatively increased $[53,54]$. In animal experiments, an increase in sclerostin-positive osteocytes within alveolar bone was linked to a decrease in bone formation in a mouse model of periodontitis $[55,56]$; in parallel, the administration of sclerostin- and DKK1-specific antibodies markedly improved alveolar bone volume and structure $[57,58]$.

Sclerostin, encoded by the SOST gene, is a kind of secreted glycoprotein primarily generated by osteocytes. In Sost knockout mice, bone thickness, bone density, and bone mechanical strength are enhanced [59], while transgenic overexpression of Sost led to osteopenia [60]. Sclerosteosis and van Buchem disease [61, 62], both caused by an absence of sclerostin, lead to excessive bone growth. DKK1 is another type of endogenous secretory protein mainly produced by osteocytes. Both sclerostin and DKK1 can negatively mediate osteoblastogenesis and osteoblastic activity by interrupting $\mathrm{Wnt} / \beta$-catenin signaling, and they compete with WNT proteins for binding to the extracellular regions of low-density lipoprotein receptor-related protein-5/6 (LRP5/6) on osteoblasts [63, 64]. DKK1 also has a catabolic function and decreases the expression of OPG by inhibiting the $\mathrm{Wnt} / \beta$-catenin signaling pathway, leading to an increased local ratio of RANKL/OPG in osteocytes, which increases osteoclastogenesis and osteoclast activity and promotes bone absorption [65-68].

Pharmaceutical therapy against sclerostin with a neutralizing monoclonal antibody (Scl-Ab) have been used for the clinical treatment of certain diseases, including osteoporosis and fracture. Romosozumab, an Scl- $\mathrm{Ab}$ agent, has completed phase III studies. Romosozumab was found to be able to reduce the threat of vertebral, hip, and other fractures in postmenopausal women suffering from osteoporosis $[69,70]$. Many studies suggest that Scl-Ab has promising prospects in the treatment of periodontitis. A mouse model with ligature-induced experimental periodontitis exhibited decreased bone volume and tissue mineral density in the local alveolar area, while after three weeks of systematic application of Scl-Ab, the indexes showed a trend of recovery and were completely reversed after six weeks, with no significant differences from the healthy control mice [71]. In parallel, a combination of anti-sclerostin and anti-DKK1 antibodies markedly improved alveolar bone volume and structure $[57,58]$, while the effect of local injection of Scl-Ab on alveolar bone recovery was limited. Similar outcomes were obtained in other studies [71-73]. In a preclinical study, the application of Scl-Ab following osteoporotic doses in the treatment of periodontitis in ovariectomized rats did not lead to ONJ [74]. The authors considered that the local inflammatory microenvironment in periodontitis may overcome the systemic osteoclast inhibition caused by sclerostin inhibition. Moreover, it has been reported that $\mathrm{ONJ}$ also presents in postmenopausal women with osteoporosis during romosozumab therapy. More and longer studies are required.

\section{Potential effect of premature osteocyte senescence on bone remodeling in periodontitis}

Osteocyte senescence is common in older individuals and is directly related to age-related bone loss or osteoporosis [75]. A small fraction of senescent cells (for instance, approximately $10-15 \%$ in aged primates) are conducive to tissue malfunction [76, 77]. However, cellular senescence can also occur in young individuals and is called premature senescence. Cellular senescence is a stress reaction to physical, chemical or biological stimulation, and it terminates the proliferation of dysfunctional cells and puts them in a state of irreversible growth stagnation $[78,79]$. This involves a series of transformations in cellular morphology and functions, such as gene expression and metabolism, as well as the development of a proinflammatory secretome or senescence-associated secretory phenotype (SASP) [80]. The accumulation of senescent osteocytes in young alveolar bone with respect to the ramus has been observed by measuring senescence-associated distension of satellites, a marker of cellular senescence, accompanied by upregulation of SASP expression [81]. Given that alveolar bone is in close contact with periodontal pathogens and their products for a long period, researchers [81] assumed that this may account for the advanced senescence of osteocytes. After in vitro and ex vivo experiments, researchers observed that LPS exposure can cause DNA damage and premature senescence in osteocytes and the resulting release of SASP through activation of P53 [81]. It is unclear whether premature LPS-induced osteocyte senescence has an influence similar to that of age-related osteocyte aging on bone remodeling and how its effects are mediated or if it acts in a specific way.

Osteocytes are the initiators of bone remodeling. Owing to the consistent pathological factors and inflammatory stimulation in periodontal tissue, osteocytes tend to become senescent and subsequently dysfunctional. This process is called inflamm-aging and may jeopardize bone remodeling and bone homeostasis [82, 83]. 
SASP, which is comprised of a variety of secretory proteins, including inflammatory cytokines, chemokines, extracellular matrix remodeling factors, and growth factors, is an important characteristic of senescent cells and has benefits, such as tumor suppression [84], but typically, it promotes chronic inflammation and/or tumorigenesis $[85,86]$. Indeed, many SASP elements, such as IL-1 $\beta$, IL-6, TNF- $\alpha$, and matrix metallopeptidase-13, were shown to inhibit osseous formation and promote osseous resorption [87, 88]. Thus, senescent cells may establish a secondary source of inflammatory factors and proteolytic factors that exacerbate alveolar bone destruction. Neutralization of these SASP components with antibodies can attenuate the pro-osteoclastogenic effects of senescent cells and restrict the generation of osteoclasts [76]. In addition, SASP is released by osteocytes in an autocrine and paracrine manner and induces secondary senescence in adjacent cells exposed to it, thereby exacerbating and amplifying the senescence and inflammatory states [89]. In the context of age-related changes in bone, senescent osteocytes exhibit dramatic degeneration of cellular processes and diminished osteocyte density, resulting in vacancies in the overall cellular connection network, which could further cause defective mechanotransduction, impaired nutrient acquisition and affected intercellular signal transduction, resulting in significant bone loss [90, 91]. In addition to expressing SASP, senescent osteocytes are also capable of inducing DNA damage and propagating senescence to bystander cells through gap junction-dependent intercellular connections; this propagated senescence is termed senescenceinduced senescence, and it creates a toxic inflammatory microenvironment to accelerate and spread its effects
[89, 92] (Fig. 4). Overall, the osteocyte senescence discovered in periodontitis and its possible repercussions may contribute to alveolar bone loss. These findings may partially explain why age acts as a risk factor for periodontitis, and treatment targeting senescent osteocytes may provide a new method to delay the progression of bone destruction in periodontitis.

\section{Osteocyte apoptosis in periodontitis}

In periodontitis, the apoptosis of inflammatory cells and periodontium cells, including osteocytes, is increased, and the apoptosis of these cells exerts a significant effect on the progression of chronic inflammation and tissue damage [93, 94]. Apoptosis is a type of programmed cell death mediated by gene expression. Apoptotic cells undergo degradation of chromatin and organelles, but the integrity of cytoplasmic membranes is maintained, and these membranes develop into apoptotic bodies and await phagocytosis and clearance by macrophages. In the last century, it has been observed that osteocytes can die very early in certain physiological or pathological conditions [95]. The death of osteocytes can modify the targeting of osteoclastogenesis followed by increased bone resorption in defined areas $[13,40,96]$.

The impact of osteocyte apoptosis can be propagated through the secretion of multiple cytokines. Osteocyte populations comprising apoptotic osteocytes produce more IL- 6 and soluble IL- 6 receptor (sIL-6R). IL- 6 can bind to sIL-6R and then form a high-affinity heterotrimer with the ubiquitously expressed transmembrane gp130, which is termed IL-6 trans signaling and widens the spectrum of affected cells to include those that do not have endogenous IL-6R [97]. When IL-6 and SIL-6R interact,

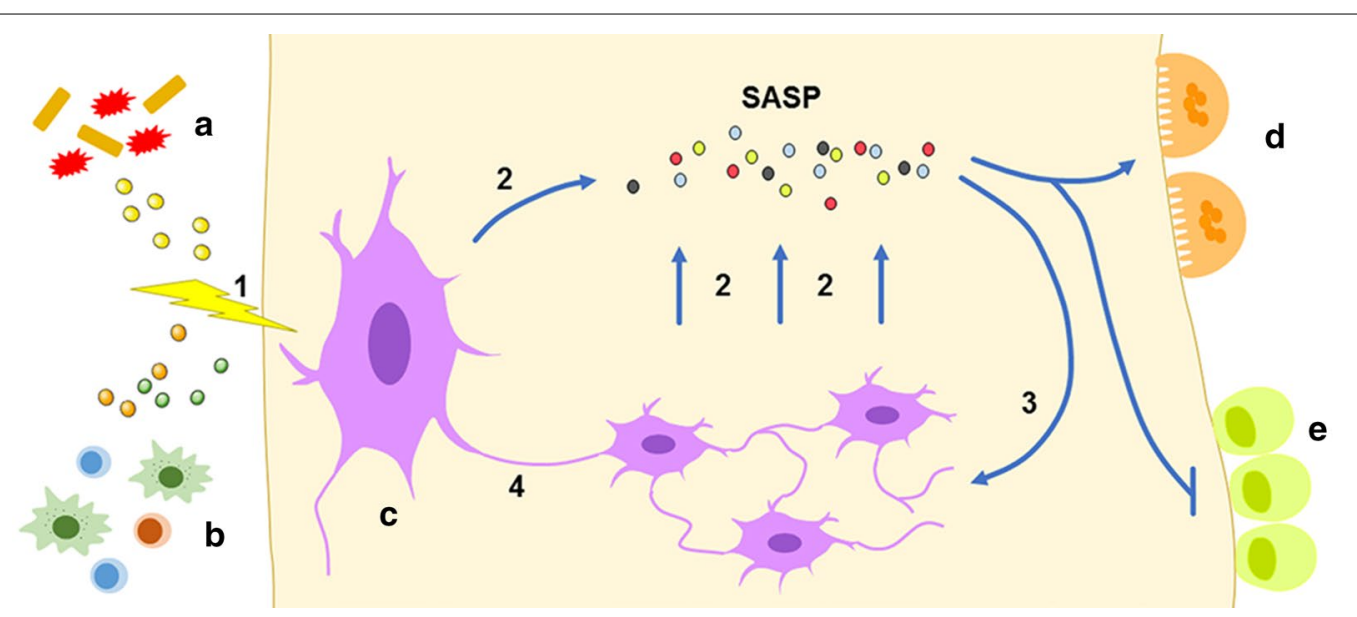

Fig. 4 Premature osteocyte senescence and its downstream effects in periodontitis. In periodontitis, stimulation by bacteria (a) and inflammatory cells (b) drives osteocytes to undergo premature senescence (1). Senescent osteocytes (c) express SASP (2), which reinforces osteoclast (d)-mediated bone resorption but inhibits osteoblast (e)-mediated bone formation. Senescent osteocytes can induce senescence in adjacent cells through SASP (3) and/or cell-cell contact (4) 
the cytoplasmic domain of gp130 binds to JAK and triggers subsequent signaling cascades, such as the JAK/ STAT pathway [31], which then activates endothelial cells to increase the expression of intercellular adhesion molecule-1 (ICAM-1), allowing osteoclast precursor cells to adhere to the vascular endothelium [98]; this is an important premise to approach the site of reconstruction. However, IL-6 can also mediate signal transduction through another alternative pathway known as classic signaling, in which a high-affinity heterotrimer forms with the membrane-bound IL-6 receptor (IL-6R) and gp130 and incorporates JAK to activate downstream signaling [31]. According to some studies, endothelial cells express little membrane-bound IL-6R, and trans-signaling may play a dominant role in this process [99]. Apoptotic osteocytes can also release adenosine triphosphate (ATP) through activated pannexin 1 channels, and ATP acts on osteocytes, osteoblasts, osteoclasts and macrophages via ATP receptor-gated (P2) channels and consequently induces enhanced production of RANKL in bystander osteocytes and osteoblasts, aggregation of macrophages, and increased osteoclastogenesis [40, 100, 101] (Fig. 5).

In addition to cytokine secretion, structural components produced by apoptotic osteocytes can also affect bone remodeling. Apoptotic bodies of dying osteocytes can promote osteoclast progenitor cells to differentiate into osteoclasts. Apoptotic osteocytes can secrete RANKL and directly modulate osteoclast formation and bone remodeling through RANKL secretion [102, 103], but in contrast, some evidence indicates that this process is not entirely dependent on RANKL because the osteoclastogenesis induced by osteocyte apoptotic bodies is not decreased in the presence of OPG concentrations ranging from $50 \mathrm{ng} / \mathrm{mL}$ to higher levels (>400 ng/ $\mathrm{mL}$ ). Interestingly, TNF- $\alpha$ produced by mononuclear osteoclast precursor cells that recognize specific markers exposed on the membranes of apoptotic osteocytes appears to be responsible for enhanced osteoclast formation [104, 105]. In addition, if apoptotic osteocytes are not cleared by macrophages in a timely manner, the cytoplasmic membrane ruptures, and this is termed secondary necrosis. This process subsequently provokes the secretion of multiple immunostimulatory cytokines and the aggregation and energization of immune cells, such as macrophages, monocytes, dendritic cells and neutrophils, which potentiates the generation of proinflammatory molecules and stimulates the secretion of RANKL in neighboring cells $[101,106]$.

At present, the reason for osteocyte apoptosis in periodontitis and its relationship to alveolar bone damage are still not clear. However, few studies have reported that bacterial stimulation and inflammatory factors can promote osteocyte apoptosis. Gingipains, toxic proteolytic enzymes secreted by Porphyromonas gingivalis, can induce transmembrane integrin $\beta 1$ degradation and inhibit Rho family GTPases, which account for the depolymerization of the cytoskeletal protein $\mathrm{F}$-actin and induce the deficiency of adherence between cells and the extracellular matrix, resulting in osteocyte apoptosis [107]. The inflammatory environment in periodontal

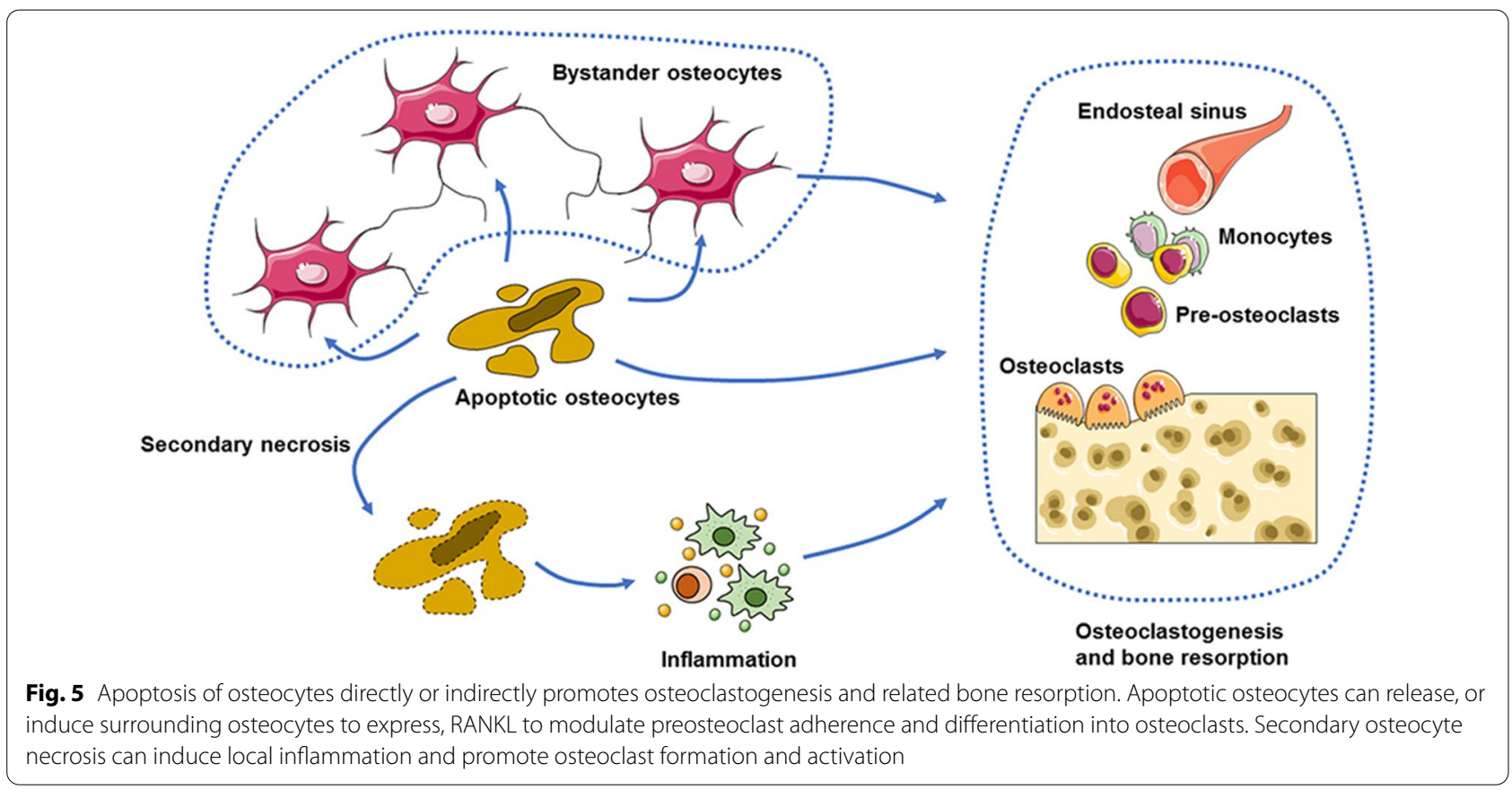


tissue is also a main cause of cell apoptosis, and the inflammatory environment caused by the death of cells can also promote osteocyte apoptosis. In periodontitis, IL-1, IL- 6 and TNF- $\alpha$ are common inflammatory cytokines confirmed to modulate osteocyte apoptosis. In an exploration of the mechanism of homocysteine (Hcy)-induced bone fragility, Hcy was found to increase IL-1 $\beta$ and IL- 6 expression by increasing NADPH oxidase (Nox) 1 and Nox2 expression, thus contributing to apoptosis of osteocyte-like cells [108]. In multiple myeloma, TNF- $\alpha$ generated by tumor cells is augmented and amplifies apoptosis of osteocytes, while neutralization of TNF- $\alpha$ failed to completely reverse this effect $[109,110]$. Furthermore, given that osteocytes are the terminal differentiation form of osteoblasts, the mechanism of osteoblast apoptosis may also provide some insight into that of osteocytes. It has been demonstrated that IL- $1 \alpha$ promotes osteoblast apoptosis and suppresses osteoblast differentiation through the activation of the JNK and p38 MAPK pathways, resulting in the exacerbation of inflammation-related bone destruction [111-113]. TNF-related apoptosis-inducing ligand (TRAIL) can also mediate osteoblast apoptosis in periodontitis owing to an imbalance between the death and decoy receptors of TRAIL, which activates caspase- 8 and caspase- 3 and consequently causes DNA degeneration [114]. These mechanisms may also provide another cause of osteocyte apoptosis. In addition to apoptosis, the functions of other death mechanisms, such as autophagy, necroptosis and nonprogrammed death, in periodontitis require further study. Elucidating the role of osteocyte death in periodontitis will bring positive significance to our comprehensive understanding of the occurrence and development of periodontitis and help to improve future clinical prevention, diagnosis and treatment of periodontitis.

\section{Osteocytes may participate in the communication between periodontitis and systemic diseases}

Periodontitis is not a simple disease that merely sweeps across the oral cavity, but rather, it has numerous correlations with general health. Systemic diseases, including DM, cardiovascular disease (CVD), RA and osteoporosis, share a bidirectional relationship with periodontitis $[4,115]$. Disorders of the internal environment caused by systemic diseases, including inflammatory state, oxidative stress, and hormone secretion dysfunction, can exacerbate the local inflammatory response and tissue destruction in periodontitis; moreover, the continuous inflammatory condition and the entrance of bacteria or their products into blood circulation may be a mechanism by which periodontitis provokes systemic pathosis [116-118]. Bone is a tissue with high vascularity, and the osteocyte network has abundant connections with blood vessels, which provides a channel for interaction between the overall internal environment and the skeletal microenvironment. The osteocyte network participates in intercommunication between bone and distant organs, such as the kidneys, muscles and other organs, and is closely related to the regulation of disease status, such as cancer metastasis [119], diabetes-related bone loss [120], and chronic kidney disease (CKD) [121] (Table 2). For example, hyperglycemia and advanced glycation endproducts (AGEs) that emerge in the chronic hyperglycemia state of DM can increase the production of sclerostin in osteocytes [51, 122]. In CKD, the apoptosis of osteocytes increases, and the expression of DMP1 decreases, followed by the upregulation of FGF23 in osteocytes, which contributes to phosphate wasting and osteomalacia [123]. The overproduction of sclerostin in osteocytes caused by a decrease in PTH levels is considered to be one of the reasons for the reduction in bone formation and mineralization failure after kidney transplantation [124]. In CKD model mice, conditional knockout of the $\mathrm{PTH} / \mathrm{PTH}$-related protein type 1 receptor (PPR) can exacerbate osteogenic deficiency at the endocortical surface but reverse bone loss on the periosteal surface [125]. In turn, osteocytes can influence the development of systemic diseases. It has been shown that conditioned medium from osteoclasts and vascular endothelial cells treated with conditioned medium from loaded osteocytes can inhibit the metastasis and promote the apoptosis of breast cancer cells [126]. In most RA and osteoarthritis (OA) patients, the expression of cyclooxygenase-2 (COX2) in osteocytes is high [127]. Induced overexpression of osteocyte COX-2 caused spontaneous OA and transgenic RA, and exclusive knockout of Cox-2 in osteocytes attenuated joint cartilage degeneration [127]. The loss or mutation of DMP1 or phosphate-regulating gene with homologies to endopeptidases on the $\mathrm{X}$ chromosome (Phex), which are both highly expressed by osteocytes, can lead to upregulation of FGF23 in osteocytes and subsequent hypophosphatemia [128, 129]. Notably, an evolving concept, termed "osteoimmunology", may play a role in this relationship. The skeletal and immune systems share many regulatory factors, which form the basis of the interaction between bone and the immune system. Some systemic diseases, such as DM and RA, can cause chronic systemic inflammation, contributing to the activation of immune cells and elevation of inflammatory substances $[130,131]$, which can exacerbate the disruption of bone homeostasis in periodontitis. For example, type 1 diabetes can elevate the proportion of $\mathrm{T}$ helper type 17 cells in the immune system and lead to an increase in the secretion of IL-17 [132, 133], which is a known proinflammatory and osteoclastogenic factor that 
Table 2 The role of osteocytes in periodontitis and other systemic diseases

\begin{tabular}{|c|c|c|c|c|c|}
\hline Influence factor & $\begin{array}{l}\text { Alteration } \\
\text { in osteocytes }\end{array}$ & Signaling pathway & Phenotype(s) & Disease status & References \\
\hline PPR knockout & - & - & $\begin{array}{l}\text { Endocortical bone forma- } \\
\text { tion } \downarrow \text {, periosteal bone } \\
\text { formation } \uparrow\end{array}$ & CKD & [125] \\
\hline $\begin{array}{l}\text { DMP1 or Phex loss/muta- } \\
\text { tion }\end{array}$ & FGF23个 & - & $\begin{array}{l}\text { Phosphate wasting } \uparrow, \\
\text { bone mineralization } \downarrow\end{array}$ & $\begin{array}{l}\text { Hypophosphatemic } \\
\text { rickets }\end{array}$ & {$[128,129]$} \\
\hline \multirow[t]{3}{*}{ Apoptosis of osteocytes } & $\mid \mathrm{IL}-6 \uparrow$ & IL-6/JAK/STAT & $\begin{array}{l}\text { I-CAM1 in endothelial } \\
\text { cells } \uparrow \text {, osteoclast } \\
\text { adherence } \uparrow\end{array}$ & Periodontitis & [98] \\
\hline & ATP $\uparrow$ & - & $\begin{array}{l}\text { RANKL } \uparrow \text { (in bystander } \\
\text { cells) }\end{array}$ & Periodontitis & {$[40,100,101]$} \\
\hline & Apoptotic bodies & - & $\begin{array}{l}\text { RANKL } \uparrow \text { (in bystander } \\
\text { cells), } \\
\text { TNF-a } \text { (in osteoclast } \\
\text { precursor cells) } \\
\text { Osteoclast differentia- } \\
\text { tion } \uparrow\end{array}$ & Periodontitis & {$[102,103]$} \\
\hline LPS & $\|-6 \uparrow, R A N K L \uparrow$ & $\begin{array}{l}\text { MAPK/ERK1/2, IL-6/JAK } \\
\text { STAT }\end{array}$ & $\begin{array}{l}\text { Osteoclast differen- } \\
\text { tiation } \uparrow, \text { bone resorp- } \\
\text { tion } \uparrow\end{array}$ & Periodontitis & [32] \\
\hline \multirow[t]{2}{*}{ TNF-a } & RANKL $\uparrow$ & $\begin{array}{l}\text { MAPK/ERK1/2/p38/JNK, } \\
\text { NF-KB signaling }\end{array}$ & $\begin{array}{l}\text { Osteoclast differen- } \\
\text { tiation } \uparrow, \text { bone resorp- } \\
\text { tion } \uparrow\end{array}$ & Periodontitis & {$[34,35]$} \\
\hline & Sclerostin $\uparrow$ & NF-KB signaling & $\begin{array}{l}\text { Osteoblast activity } \downarrow \text {, } \\
\text { bone formation } \downarrow\end{array}$ & Periodontitis & {$[35,49]$} \\
\hline Hyperglycemia and AGEs & Sclerostin $\uparrow$ & - & $\begin{array}{l}\text { Osteoblast activity } \downarrow \text {, } \\
\text { bone formation } \downarrow\end{array}$ & DM-related periodontitis & {$[51,122]$} \\
\hline PTH $\downarrow$ & Sclerostin $\uparrow$ & - & $\begin{array}{l}\text { Bone formation } \downarrow \text {, bone } \\
\text { mineralization } \downarrow\end{array}$ & $\begin{array}{l}\text { Kidney transplantation } \\
\text { complication }\end{array}$ & [124] \\
\hline Loading & - & - & $\begin{array}{r}\text { Metastasis } \downarrow \text {, apoptosis } \uparrow \\
\quad \text { (in breast cancer cells) }\end{array}$ & Breast cancer & [126] \\
\hline- & $\operatorname{coX}-2 \uparrow$ & - & $\begin{array}{l}\text { Joint cartilage degenera- } \\
\text { tion } \uparrow\end{array}$ & OA, RA & {$[127]$} \\
\hline- & DMP-1个, FGF23 $\downarrow$ & - & $\begin{array}{l}\text { Phosphate wasting } \uparrow, \\
\text { osteomalacia }\end{array}$ & CKD & [123] \\
\hline
\end{tabular}

promotes RANKL production in osteoblasts [134, 135]. However, the specific role of osteocytes in the immune system is still not clear. Based on the above, osteocytes may provide a new approach to describe the interplay of periodontitis and systemic disease, and we recommend future research focusing on the junctional role of the osteocyte network.

\section{The role of other cells with osteoblast-like characteristics in bone loss in periodontitis}

In addition to osteocytes, other cells with osteoblastic properties may also be involved in periodontitis-related bone destruction. Periodontal ligament cells (PDLCs), capable of expressing alkaline phosphatase and boneassociated proteins, are osteoblast-like cells [136]. It has been reported that PDLCs can enhance osteoclast formation and accelerate bone resorption in response to certain stimuli through the enhanced activation of the TLR4 pathway and higher expression of inflammatory cytokines, including RANKL, TNF- $\alpha$, macrophagecolony stimulating factor, IL-6, IL- $1 \beta$, and CXC motif chemokine 2 [137-140]. The ability of PDLCs to promote inflammation and osteoclast formation can be inhibited when NF- $\mathrm{kB}$ signaling is inhibited by the induction of the exclusive expression of a dominant negative mutant of IK kinase [140]. This characteristic of PDLCs can also be enforced by the inhibition of orthodontic force-induced tooth movement and osteoclastogenesis in transgenic mice in which RANKL was deleted in PDLCs and bone lining cells [141]. In addition to PDLCs, gingival fibroblasts (GFs) can also be stimulated to differentiate into the osteogenic lineage, although their osteogenic capacity is weaker than that of PDLCs [142]. GFs can express osteopontin and osteocalcin, leading to mineralization under dexamethasone treatment [143]. To some extent, GFs also have the potential to inhibit osteoclastogenesis compared to PDLCs [144]. Stimulating GFs with TLR2 and TLR4 agonists does not affect their osteogenic capacity 
but significantly inhibits their ability to promote osteoclast formation [145].

Furthermore, periodontal ligament stem cells (PDLSCs) and gingival mesenchymal stem cells (GMSCs) also exhibit enhanced osteogenic differentiation potential and are widely studied in skeletal tissue engineering research [146]. PDLSCs can exhibit increased proliferation and mineral deposition in response to some treatments, such as kaempferol and curcumin [147, 148]. GMSCs can adhere to a titanium surface and deposit mineralized tissue, which resembles native bone [149]. In combination with biocompatible materials, these cells show promising application prospects in periodontal bone regeneration $[150,151]$.

These results suggest that other periodontal cells with osteoblast-like characteristics, such as osteoblasts, osteoclasts and osteocytes, may also play an important role in the destruction of alveolar bone. Elucidating their roles will help us better understand the pathological mechanism of periodontitis and provide new targets for treatment of periodontitis.

\section{Conclusions}

In recent years, the regulatory effect of osteocytes in physiological and pathological processes has received increasing attention. Here, we summarize the latest research discoveries on the mechanism by which osteocytes promote alveolar bone loss in periodontitis. Osteocytes, with their unique structural and functional characteristics, are important for pathological alveolar bone remodeling in periodontitis and may facilitate the interaction between periodontitis and systemic diseases. Other cells with osteoblastic properties may also play a role in promoting periodontitis development. Hence, research on osteocytes and other cells could shed light on the mechanism underlying tissue destruction in periodontitis and provide a new target for the effective management and treatment of periodontitis as well as tissue regeneration therapy.

\footnotetext{
Abbreviations

AGEs: Advanced glycation end-products; AMPK: AMP-activated protein kinase; ATP: Adenosine triphosphate; BMMs: Bone marrow macrophages; CKD: Chronic kidney disease; COX-2: Cyclooxygenase-2; CSF: Colony-stimulating factor; CVDs: Cardiovascular disease; DKK1: Dickkopf-related protein 1; DM: Diabetes mellitus; DMP1: Dentin matrix protein 1; ERK: Extracellular signalregulated kinase; FGF23: Fibroblast growth factor 23; GFs: Gingival fibroblasts; GMSCs: Gingival mesenchymal stem cells; F-actin: Actin filaments; Hcy: Homocysteine; ICAM-1: Intercellular adhesion molecule-1; IL: Interleukin IL-6R: IL-6 receptor; JAK: Janus kinase; JNK: Jun kinase; LCS: Lacuno-canalicular system; LPS: Lipopolysaccharide; LRP5/6: Low-density lipoprotein receptorrelated protein-5/6; MAPK: Mitogen-activated protein kinase; NF-kB: Nuclear factor-kappa B; Nox: NADPH oxidase; OA: Osteoarthritis; ONJ: Osteonecrosis of the jaw; OPG: Osteoprotegerin; PDLCs: Periodontal ligament cells; PDLSCs: Periodontal ligament stem cells; Phex: Phosphate-regulating gene with homologies to endopeptidases on the X chromosome; PPR: PTH/PTH-related
}

protein type 1 receptor; PTH: Parathyroid hormone; RA: Rheumatoid arthritis; RANK: Receptor activator of NF-KB; RANKL: Receptor activator of NF-KB ligand; SASP: Senescence-associated secretory phenotype; Scl-Ab: Sclerostin antibody; SIL-6R: Soluble IL-6 receptor; STAT: Signal transducer and activator of transcription; TLR: Toll-like receptor; TNF-a: Tumor necrosis factor-a; TRAIL: TNF-related apoptosis-inducing ligand.

\section{Acknowledgements}

Not applicable.

\section{Authors' contributions}

$\mathrm{XH}$ and $\mathrm{MX}$ performed the original draft preparation, revision, created the tables and figures, and were the major contributors in writing the manuscript. $Y X, F M$, and $X L$ made suggestions to the writing of the manuscript and revisions to tables and figures. XL and LC participated in conceptualization and methodology. LC supervised the work and acquired funding. All authors read and approved the final manuscript.

\section{Funding}

This work was supported by the National Science Foundation for Distinguished Young Scholars of China (31725011 to Lili Chen).

Availability of data and materials

Not applicable.

Ethics approval and consent to participate

Not applicable.

\section{Consent for publication}

Not applicable.

\section{Competing interests}

The authors declare that they have no competing interests.

\section{Author details}

${ }^{1}$ Department of Stomatology, Union Hospital, Tongji Medical College, Huazhong University of Science and Technology, Wuhan 430022, China. ${ }^{2}$ Hubei Province Key Laboratory of Oral and Maxillofacial Development and Regeneration, Wuhan 430022, China.

Received: 28 August 2020 Accepted: 3 December 2020

Published online: 11 December 2020

\section{References}

1. Peres MA, Macpherson LMD, Weyant RJ, Daly B, Venturelli R, Mathur $M R$, et al. Oral diseases: a global public health challenge. The Lancet. 2019;394(10194):249-60. https://doi.org/10.1016/s0140-6736(19)31146 -8 .

2. Kassebaum NJ, Bernabe E, Dahiya M, Bhandari B, Murray CJ, Marcenes W. Global burden of severe periodontitis in 1990-2010: a systematic review and meta-regression. J Dent Res. 2014;93(11):1045-53. https:// doi.org/10.1177/0022034514552491.

3. Xie M, Tang Q, Nie J, Zhang C, Zhou X, Yu S, et al. BMAL1-downregulation aggravates -induced atherosclerosis by encouraging oxidative stress. Circ Res. 2020;126(6):e15-29. https://doi.org/10.1161/CIRCR ESAHA.119.315502.

4. Preshaw PM, Alba AL, Herrera D, Jepsen S, Konstantinidis A, Makrilakis K, et al. Periodontitis and diabetes: a two-way relationship. Diabetologia. 2012;55(1):21-31. https://doi.org/10.1007/s00125-011-2342-y.

5. Araújo VMA, Melo IM, Lima V. Relationship between Periodontitis and Rheumatoid Arthritis: Review of the Literature. Mediat Inflamm. 2015;2015:259074. https://doi.org/10.1155/2015/259074.

6. Wang CJ, MCCauley LK. Osteoporosis and periodontitis. Curr Osteoporos Rep. 2016;14(6):284-91. https://doi.org/10.1007/s1191 4-016-0330-3.

7. Vignery A, Baron R. Dynamic histomorphometry of alveolar bone remodeling in the adult rat. The Anatomical Record. 1980;196(2):191200. https://doi.org/10.1002/ar.1091960210. 
8. Graves DT, Alshabab A, Albiero ML, Mattos M, Correa JD, Chen SS, et al. Osteocytes play an important role in experimental periodontitis in healthy and diabetic mice through expression of RANKL. J Clin Periodontol. 2018;45(3):285-92. https://doi.org/10.1111/jcpe.12851.

9. Thorbert-Mros S, Larsson L, Berglundh T. Cellular composition of long-standing gingivitis and periodontitis lesions. J Periodontal Res. 2015;50(4):535-43. https://doi.org/10.1111/jre.12236.

10. Kononen E, Gursoy M, Gursoy UK. Periodontitis: A Multifaceted Disease of Tooth-Supporting Tissues. J Clin Med. 2019;8(8). doi:https://doi. org/10.3390/jcm8081135.

11. Hienz SA, Paliwal S, Ivanovski S. Mechanisms of Bone Resorption in Periodontitis. J Immunol Res. 2015;2015:615486. https://doi. org/10.1155/2015/615486.

12. Schulze-Spate U, Turner R, Wang Y, Chao R, Schulze PC, Phipps K, et al. Relationship of Bone Metabolism Biomarkers and Periodontal Disease: The Osteoporotic Fractures in Men (MrOS) Study. J Clin Endocrinol Metab. 2015;100(6):2425-33. https://doi.org/10.1210/jc.2014-4180.

13. Tatsumi S, Ishii K, Amizuka N, Li M, Kobayashi T, Kohno K, et al. Targeted ablation of osteocytes induces osteoporosis with defective mechanotransduction. Cell Metab. 2007;5(6):464-75. https://doi.org/10.1016/j. cmet.2007.05.001.

14. Kang KS, Hong JM, Robling AG. Postnatal $\beta$-catenin deletion from Dmp1-expressing osteocytes/osteoblasts reduces structural adaptation to loading, but not periosteal load-induced bone formation. Bone. 2016:88:138-45. https://doi.org/10.1016/j.bone.2016.04.028.

15. Nakashima T, Hayashi M, Fukunaga T, Kurata K, Oh-Hora M, Feng $\mathrm{JQ}$, et al. Evidence for osteocyte regulation of bone homeostasis through RANKL expression. Nat Med. 2011;17(10):1231-4. https://doi. org/10.1038/nm.2452.

16. Werner SL, Sharma R, Woodruff K, Horn D, Harris SE, Gorin Y, et al. CSF-1 in osteocytes inhibits Nox4-mediated oxidative stress and promotes normal bone homeostasis. JBMR Plus. 2020;4(7):e10080. https://doi. org/10.1002/jbm4.10080.

17. Joeng KS, Lee YC, Lim J, Chen Y, Jiang MM, Munivez E, et al. Osteocytespecific WNT1 regulates osteoblast function during bone homeostasis. J Clin Invest. 2017;127(7):2678-88. https://doi.org/10.1172/JC192617.

18. Robling AG, Bonewald LF. The osteocyte: new insights. Annu Rev Physiol. 2020;82:485-506. https://doi.org/10.1146/annurev-physi ol-021119-034332.

19. Lai X, Price C, Modla S, Thompson WR, Caplan J, Kirn-Safran CB, et al. The dependences of osteocyte network on bone compartment, age, and disease. Bone Res. 2015. https://doi.org/10.1038/boneres.2015.9.

20. Uda Y, Azab E, Sun N, Shi C, Pajevic PD. Osteocyte Mechanobiology. Curr Osteop Rep. 2017;15(4):318-25. https://doi.org/10.1007/s1191 4-017-0373-0.

21. Kenkre JS, Bassett JHD. The bone remodelling cycle. Ann Clin Biochem. 2018;55(3):308-27. https://doi.org/10.1177/0004563218759371.

22. Plotkin LI, Gortazar AR, Davis HM, Condon KW, Gabilondo H, Maycas $\mathrm{M}$, et al. Inhibition of osteocyte apoptosis prevents the increase in osteocytic receptor activator of nuclear factor KB ligand (RANKL) but does not stop bone resorption or the loss of bone induced by unloading. J Biol Chem. 2015;290(31):18934-42. https://doi.org/10.1074/jbc. M115.642090

23. Kramer I, Keller H, Leupin O, Kneissel M. Does osteocytic SOST suppression mediate PTH bone anabolism? Trends Endocrinol Metab. 2010;21(4):237-44. https://doi.org/10.1016/j.tem.2009.12.002.

24. de Diego C, Artigas N, Pimenta-Lopes C, Valer JA, Torrejon B, GamaPérez P, et al. Glucose Restriction Promotes Osteocyte Specification by Activating a PGC-1a-Dependent Transcriptional Program. iScience. 2019;15:79-94. https://doi.org/10.1016/j.isci.2019.04.015.

25. Xiong J, Piemontese M, Onal M, Campbell J, Goellner JJ, Dusevich V, et al. Osteocytes, not osteoblasts or lining cells, are the main source of the RANKL required for osteoclast formation in remodeling bone. PLoS ONE. 2015;10(9):e0138189. https://doi.org/10.1371/journal.pone.01381 89.

26. Martin TJ, Sims NA. RANKL/OPG; Critical role in bone physiology. Rev Endocr Metab Disord. 2015;16(2):131-9. https://doi.org/10.1007/s1115 4-014-9308-6.

27. Bivi N, Condon KW, Allen MR, Farlow N, Passeri G, Brun LR, et al. Cell autonomous requirement of connexin 43 for osteocyte survival: consequences for endocortical resorption and periosteal bone formation. J Bone Mineral Res. 2012;27(2):374-89. https://doi.org/10.1002/ jbmr.548.

28. Monroe DG, McGee-Lawrence ME, Oursler MJ, Westendorf JJ. Update on Wnt signaling in bone cell biology and bone disease. Gene. 2012;492(1):1-18. https://doi.org/10.1016/j.gene.2011.10.044.

29. Hill TP, Später D, Taketo MM, Birchmeier W, Hartmann C. Canonical Wnt/ beta-catenin signaling prevents osteoblasts from differentiating into chondrocytes. Dev Cell. 2005;8(5):727-38. https://doi.org/10.1016/j. devcel.2005.02.013.

30. Sakamoto E, Kido Jl, Takagi R, Inagaki Y, Naruishi K, Nagata T, et al. Advanced glycation end-product 2 and Porphyromonas gingivalis lipopolysaccharide increase sclerostin expression in mouse osteocyte-like cells. Bone. 2019;122:22-30. https://doi.org/10.1016/j. bone.2019.02.001.

31. Mihara M, Hashizume M, Yoshida H, Suzuki M, Shiina M. IL-6/LL-6 receptor system and its role in physiological and pathological conditions. Clin Sci (Lond). 2012;122(4):143-59. https://doi.org/10.1042/CS20110340.

32. Yu K, Ma Y, Li X, Wu X, Liu W, Li X, et al. Lipopolysaccharide increases IL-6 secretion via activation of the ERK $1 / 2$ signaling pathway to up-regulate RANKL gene expression in MLO-Y4 cells. Cell Biol Int. 2017;41 (1):84-92. https://doi.org/10.1002/cbin.10696.

33. Kulkarni RN, Bakker AD, Everts V, Klein-Nulend J. Mechanical loading prevents the stimulating effect of IL-1 $\beta$ on osteocyte-modulated osteoclastogenesis. Biochem Bioph Res Co. 2012;420(1):11-6. https:// doi.org/10.1016/j.bbrc.2012.02.099.

34. Marahleh A, Kitaura H, Ohori F, Kishikawa A, Ogawa S, Shen WR, et al. TNF-alpha Directly Enhances Osteocyte RANKL Expression and Promotes Osteoclast Formation. Front Immunol. 2019;10:2925. https://doi. org/10.3389/fimmu.2019.02925.

35. Pacios S, Xiao W, Mattos M, Lim J, Tarapore RS, Alsadun S, et al. Osteoblast lineage cells play an essential role in periodontal bone loss through activation of nuclear factor-kappa B. Sci Rep. 2015;5:16694. https://doi.org/10.1038/srep16694.

36. Liu D, Xu JK, Figliomeni L, Huang L, Pavlos NJ, Rogers M, et al. Expression of RANKL and OPG mRNA in periodontal disease: possible involvement in bone destruction. Int J Mol Med. 2003;11(1):17-21. https://doi. org/10.3892/ijmm.11.1.17.

37. Boyce BF, Xing L. Functions of RANKL/RANK/OPG in bone modeling and remodeling. Arch Biochem Biophys. 2008;473(2):139-46. https://doi. org/10.1016/j.abb.2008.03.018.

38. Kanzaki H, Makihira S, Suzuki M, Ishii T, Movila A, Hirschfeld J, et al. Soluble RANKL Cleaved from Activated Lymphocytes by TNF-a-Converting Enzyme Contributes to Osteoclastogenesis in Periodontitis. J Immunol. 2016;197(10):3871-83. https://doi.org/10.4049/jimmunol.1601114.

39. Kawai T, Matsuyama T, Hosokawa Y, Makihira S, Seki M, Karimbux NY, et al. B and T lymphocytes are the primary sources of RANKL in the bone resorptive lesion of periodontal disease. Am J Pathol. 2006;169(3):987-98. https://doi.org/10.2353/ajpath.2006.060180.

40. Xiong J, Onal M, Jilka RL, Weinstein RS, Manolagas SC, O'Brien CA. Matrix-embedded cells control osteoclast formation. Nat Med. 2011;17(10):1235-41. https://doi.org/10.1038/nm.2448.

41. Honma M, Ikebuchi Y, Kariya Y, Hayashi M, Hayashi N, Aoki S, et al. RANKL subcellular trafficking and regulatory mechanisms in osteocytes. J Bone Miner Res. 2013;28(9):1936-49. https://doi.org/10.1002/ jbmr.1941.

42. Seeman E, Delmas PD. Bone quality-the material and structural basis of bone strength and fragility. N Engl J Med. 2006;354(21):2250-61. https ://doi.org/10.1056/NEJMra053077.

43. Kuritani M, Sakai N, Karakawa A, Isawa M, Chatani M, Negishi-Koga T, et al. Anti-mouse RANKL Antibodies Inhibit Alveolar Bone Destruction in Periodontitis Model Mice. Biol Pharm Bull. 2018;41(4):637-43. https:// doi.org/10.1248/bpb.b18-00026.

44. Jin Q, Cirelli JA, Park CH, Sugai JV, Taba M Jr, Kostenuik PJ, et al. RANKL inhibition through osteoprotegerin blocks bone loss in experimental periodontitis. J Periodontol. 2007;78(7):1300-8. https://doi.org/10.1902/ jop.2007.070073.

45. Kennel KA, Drake MT. Adverse effects of bisphosphonates: implications for osteoporosis management. Mayo Clin Proc. 2009;84(7):632-8. https ://doi.org/10.4065/84.7.632. 
46. Sigua-Rodriguez EA, da Costa RR, de Brito AC, Alvarez-Pinzon N, de Albergaria-Barbosa JR. Bisphosphonate-related osteonecrosis of the jaw: a review of the literature. Int J Dent. 2014;2014:192320. https://doi. org/10.1155/2014/192320.

47. Boquete-Castro A, Gomez-Moreno G, Calvo-Guirado JL, AguilarSalvatierra A, Delgado-Ruiz RA. Denosumab and osteonecrosis of the jaw. A systematic analysis of events reported in clinical trials. Clin Oral Implants Res. 2016;27(3):367-75. https://doi.org/10.1111/clr.12556.

48. Beth-Tasdogan NH, Mayer B, Hussein $\mathrm{H}$, Zolk O. Interventions for managing medication-related osteonecrosis of the jaw. Cochrane Database Syst Rev. 2017;10:012432. https://doi.org/10.1002/14651858.CD012432. pub2.

49. Baek K, Hwang HR, Park HJ, Kwon A, Qadir AS, Ko SH, et al. TNF-alpha upregulates sclerostin expression in obese mice fed a high-fat diet. $J$ Cell Physiol. 2014;229(5):640-50. https://doi.org/10.1002/jcp.24487.

50. Heiland GR, Zwerina K, Baum W, Kireva T, Distler JH, Grisanti M, et al. Neutralisation of Dkk-1 protects from systemic bone loss during inflammation and reduces sclerostin expression. Ann Rheum Dis. 2010;69(12):2152-9. https://doi.org/10.1136/ard.2010.132852.

51. Sakamoto E, Kido J, Takagi R, Inagaki Y, Naruishi K, Nagata T, et al. Advanced glycation end-product 2 and Porphyromonas gingivalis lipopolysaccharide increase sclerostin expression in mouse osteocyte-like cells. Bone. 2019;122:22-30. https://doi.org/10.1016/j. bone.2019.02.001.

52. Rezaei Esfahrood Z, Yadegari Z, Veysari SK, Kadkhodazadeh M. Gingival crevicular fluid levels of sclerostin in chronic periodontitis and healthy subjects. J Kor Assoc Oral Maxil Surg. 2018;44(6):289-92. https://doi. org/10.5125/jkaoms.2018.44.6.289.

53. Napimoga MH, Nametala C, da Silva FL, Miranda TS, Bossonaro JP, Demasi AP, et al. Involvement of the Wnt- $\beta$-catenin signalling antagonists, sclerostin and dickkopf-related protein 1, in chronic periodontitis. J Clin Periodontol. 2014;41(6):550-7. https://doi.org/10.1111/jcpe.12245

54. Sankardas PA, Lavu V, Lakakula B, Rao SR. Differential expression of periostin, sclerostin, receptor activator of nuclear factor-kB, and receptor activator of nuclear factor-kB ligand genes in severe chronic periodontitis. J Invest Clin Dent. 2019;10(1):e12369. https://doi.org/10.1111/ jicd.12369.

55. Kim JH, Lee DE, Woo GH, Cha JH, Bak EJ, Yoo YJ. Osteocytic Sclerostin expression in alveolar bone in rats with diabetes mellitus and ligatureinduced periodontitis. J Periodontol. 2015;86(8):1005-11. https://doi. org/10.1902/jop.2015.150083.

56. Kim J-H, Lee D-E, Cha J-H, Bak E-J, Yoo Y-J. Receptor activator of nuclear factor-kB ligand and sclerostin expression in osteocytes of alveolar bone in rats with ligature-induced periodontitis. J Periodontol. 2014;85(11):e370-8. https://doi.org/10.1902/jop.2014.140230.

57. Liu M, Kurimoto P, Zhang J, Niu QT, Stolina M, Dechow PC, et al. Sclerostin and DKK1 inhibition preserves and augments alveolar bone volume and architecture in rats with alveolar bone loss. J Dent Res. 2018;97(9):1031-8. https://doi.org/10.1177/0022034518766874.

58. Witcher PC, Miner SE, Horan DJ, Bullock WA, Lim KE, Kang KS, et al. Sclerostin neutralization unleashes the osteoanabolic effects of Dkk1 inhibition. Jci Insight. 2018:3:11. https://doi.org/10.1172/jci.insight.98673.

59. Kuchler U, Schwarze UY, DobsakT, Heimel P, Bosshardt DD, Kneissel M, et al. Dental and periodontal phenotype in sclerostin knockout mice. Int J Oral Sci. 2014;6(2):70-6. https://doi.org/10.1038/ijos.2014.12.

60. Kramer I, Loots GG, Studer A, Keller H, Kneissel M. Parathyroid hormone (PTH)-induced bone gain is blunted in SOST overexpressing and deficient mice. J Bone Min Res. 2010;25(2):178-89. https://doi.org/10.1359/ jbmr.090730.

61. Balemans W, Cleiren E, Siebers U, Horst J, Van Hul W. A generalized skeletal hyperostosis in two siblings caused by a novel mutation in the SOST gene. Bone. 2005;36(6):943-7. https://doi.org/10.1016/j. bone.2005.02.019.

62. Brunkow ME, Gardner JC, Van Ness J, Paeper BW, Kovacevich BR, Proll $\mathrm{S}$, et al. Bone dysplasia sclerosteosis results from loss of the SOST gene product, a novel cystine knot-containing protein. Am J Hum Genet. 2001;68(3):577-89. https://doi.org/10.1086/318811.

63. Li X, Zhang Y, Kang H, Liu W, Liu P, Zhang J, et al. Sclerostin binds to LRP5/6 and antagonizes canonical Wnt signaling. J Biol Chem. 2005;280(20):19883-7. https://doi.org/10.1074/jbc.M413274200.
64. Tan X, Huang D, Zhou W, Yan L, Yue J, Lu W, et al. Dickkopf-1 may regulate bone coupling by attenuating wnt/beta-catenin signaling in chronic apical periodontitis. Arch Oral Biol. 2018;86:94-100. https://doi. org/10.1016/j.archoralbio.2017.11.012.

65. Wijenayaka AR, Kogawa M, Lim HP, Bonewald LF, Findlay DM, Atkins GJ. Sclerostin stimulates osteocyte support of osteoclast activity by a RANKL-dependent pathway. PLoS ONE. 2011;6(10):e25900. https://doi. org/10.1371/journal.pone.0025900.

66. Tian X, Jee WS, Li X, Paszty C, Ke HZ. Sclerostin antibody increases bone mass by stimulating bone formation and inhibiting bone resorption in a hindlimb-immobilization rat model. Bone. 2011;48(2):197-201. https ://doi.org/10.1016/j.bone.2010.09.009.

67. Hesse E, Schroder S, Brandt D, Pamperin J, Saito H, Taipaleenmaki H. Sclerostin inhibition alleviates breast cancer-induced bone metastases and muscle weakness. Jci Insight. 2019. https://doi.org/10.1172/jci.insig ht.125543.

68. Goes P, Dutra C, Lösser L, Hofbauer LC, Rauner M, Thiele S. Loss of Dkk-1 in osteocytes mitigates alveolar bone loss in mice with periodontitis. Front Immunol. 2019;10:2924. https://doi.org/10.3389/fimmu .2019.02924.

69. Shoback D, Rosen CJ, Black DM, Cheung AM, Murad MH, Eastell R. Pharmacological management of osteoporosis in postmenopausal women: an endocrine society guideline update. J Clin Endocrinol Metab. 2020;105:3. https://doi.org/10.1210/clinem/dgaa048.

70. Iolascon G, Moretti A, Toro G, Gimigliano F, Liguori S, Paoletta M. Pharmacological therapy of osteoporosis: what's new? Clin Interv Aging. 2020;15:485-91. https://doi.org/10.2147/CIA.S242038.

71. Taut AD, Jin Q, Chung JH, Galindo-Moreno P, Yi ES, Sugai JV, et al. Sclerostin antibody stimulates bone regeneration after experimental periodontitis. J Bone Miner Res. 2013;28(11):2347-56. https://doi. org/10.1002/jbmr.1984.

72. Ren YS, Han XL, Ho SP, Harris SE, Cao ZG, Economides AN, et al. Removal of SOST or blocking its product sclerostin rescues defects in the periodontitis mouse model. Faseb J. 2015;29(7):2702-11. https://doi. org/10.1096/fj.14-265496.

73. Chen H, Xu X, Liu M, Zhang W, Ke HZ, Qin A, et al. Sclerostin antibody treatment causes greater alveolar crest height and bone mass in an ovariectomized rat model of localized periodontitis. Bone. 2015;76:1418. https://doi.org/10.1016/j.bone.2015.04.002.

74. Hadaya D, Gkouveris I, Soundia A, Bezouglaia O, Boyce RW, Stolina M, et al. Clinically relevant doses of sclerostin antibody do not induce osteonecrosis of the jaw (ONJ) in rats with experimental periodontitis. J Bone Min Res. 2019;34(1):171-81. https://doi.org/10.1002/jbmr.3581.

75. Hemmatian H, Bakker AD, Klein-Nulend J, van Lenthe GH. Aging, osteocytes, and mechanotransduction. Curr Osteoporos Rep. 2017;15(5):40111. https://doi.org/10.1007/s11914-017-0402-z.

76. Farr JN, Xu M, Weivoda MM, Monroe DG, Fraser DG, Onken JL, et al. Targeting cellular senescence prevents age-related bone loss in mice. Nat Med. 2017;23(9):1072-9. https://doi.org/10.1038/nm.4385.

77. Herbig U, Ferreira M, Condel L, Carey D, Sedivy JM. Cellular senescence in aging primates. Science (New York, NY). 2006;311(5765):1257. https:// doi.org/10.1126/science.1122446.

78. Tchkonia T, Zhu Y, van Deursen J, Campisi J, Kirkland JL. Cellular senescence and the senescent secretory phenotype: therapeutic opportunities. J Clin Investig. 2013;123(3):966-72. https://doi.org/10.1172/JCl64 098.

79. Childs BG, Durik M, Baker DJ, van Deursen JM. Cellular senescence in aging and age-related disease: from mechanisms to therapy. Nat Med. 2015;21(12):1424-35. https://doi.org/10.1038/nm.4000.

80. Farr JN, Khosla S. Cellular senescence in bone. Bone. 2019;121:121-33. https://doi.org/10.1016/j.bone.2019.01.015.

81. Aquino-Martinez R, Rowsey JL, Fraser DG, Eckhardt BA, Khosla S, Far JN, et al. LPS-induced premature osteocyte senescence: Implications in inflammatory alveolar bone loss and periodontal disease pathogenesis. Bone. 2020;132:115220. https://doi.org/10.1016/j.bone.2019.115220.

82. Eckhardt BA, Rowsey JL, Thicke BS, Fraser DG, O'Grady KL, Bondar OP, et al. Accelerated osteocyte senescence and skeletal fragility in mice with type 2 diabetes. Jci Insight. 2020. https://doi.org/10.1172/jci.insig ht.135236.

83. Franceschi C, Bonafè M, Valensin S, Olivieri F, De Luca M, Ottaviani $E$, et al. Inflamm-aging. An evolutionary perspective on 
immunosenescence. Ann New York Acad Sci. 2000;908:244-54. https:// doi.org/10.1111/j.1749-6632.2000.tb06651.x.

84. Kuilman T, Michaloglou C, Vredeveld LCW, Douma S, van Doorn R, Desmet $C J$, et al. Oncogene-induced senescence relayed by an interleukindependent inflammatory network. Cell. 2008;133(6):1019-31. https:// doi.org/10.1016/j.cell.2008.03.039.

85. Coppé J-P, Patil CK, Rodier F, Sun Y, Muñoz DP, Goldstein J, et al. Senescence-associated secretory phenotypes reveal cell-nonautonomous functions of oncogenic RAS and the p53 tumor suppressor. PLoS Biol. 2008;6(12):2853-68. https://doi.org/10.1371/journal.pbio.0060301.

86. Watanabe S, Kawamoto S, Ohtani N, Hara E. Impact of senescence-associated secretory phenotype and its potential as a therapeutic target for senescence-associated diseases. Cancer Sci. 2017;108(4):563-9. https:// doi.org/10.1111/cas.13184.

87. Prattichizzo F, De Nigris V, La Sala L, Procopio AD, Olivieri F, Ceriello A. "Inflammaging" as a druggable target: a senescence-associated secretory phenotype-centered view of type 2 diabetes. Oxid Med Cell Longev. 2016;2016:1810327. https://doi.org/10.1155/2016/1810327.

88. Sims NA. Senescent osteocytes: do they cause damage and can they be targeted to preserve the skeleton? J Bone Miner Res. 2016;31(11):19179. https://doi.org/10.1002/jbmr.2994.

89. Kirschner K, Rattanavirotkul N, Quince MF, Chandra T. Functional heterogeneity in senescence. Biochem Soc Trans. 2020. https://doi. org/10.1042/BST20190109.

90. Holguin N, Brodt MD, Silva MJ. Activation of Wnt signaling by mechanical loading is impaired in the bone of old mice. J Bone Miner Res. 2016;31(12):2215-26. https://doi.org/10.1002/jbmr.2900.

91. Tiede-Lewis LM, Xie Y, Hulbert MA, Campos R, Dallas MR, Dusevich V, et al. Degeneration of the osteocyte network in the C57BL/6 mouse model of aging. Aging. 2017;9(10):2190-208. https://doi.org/10.18632/ aging. 101308

92. Farr JN, Fraser DG, Wang H, Jaehn K, Ogrodnik MB, Weivoda MM, et al. Identification of senescent cells in the bone microenvironment. J Bone Miner Res. 2016;31(11):1920-9. https://doi.org/10.1002/jbmr.2892.

93. Jun HK, Jung YJ, Choi BK. Treponema denticola, Porphyromonas gingivalis, and Tannerella forsythia induce cell death and release of endogenous danger signals. Arch Oral Biol. 2017;73:72-8. https://doi.org/10.1016/j. archoralbio.2016.09.010.

94. Fu YW, He HB. Apoptosis of periodontium cells in streptozototocinand ligature-induced experimental diabetic periodontitis in rats. Acta Odontol Scand. 2013;71(5):1206-15. https://doi.org/10.3109/00016 357.2012 .757638$.

95. Noble BS, Stevens H, Loveridge N, Reeve J. Identification of apoptotic changes in osteocytes in normal and pathological human bone. Bone. 1997;20(3):273-82. https://doi.org/10.1016/s8756-3282(96)00365-1.

96. Noble BS, Peet N, Stevens HY, Brabbs A, Mosley JR, Reilly GC, et al. Mechanical loading: biphasic osteocyte survival and targeting of osteoclasts for bone destruction in rat cortical bone. Am J Physiol Cell Physiol. 2003;284(4):C934-43. https://doi.org/10.1152/ajpcell.00234 .2002 .

97. Rose-John S. The soluble interleukin 6 receptor: advanced therapeutic options in inflammation. Clin Pharmacol Ther. 2017;102(4):591-8. https ://doi.org/10.1002/cpt.782.

98. Cheung WY, Simmons CA, You L. Osteocyte apoptosis regulates osteoclast precursor adhesion via osteocytic IL-6 secretion and endothelial ICAM-1 expression. Bone. 2012;50(1):104-10. https://doi.org/10.1016/j. bone.2011.09.052

99. Romano M, Sironi M, Toniatti C, Polentarutti N, Fruscella P, Ghezzi P, et al. Role of IL-6 and its soluble receptor in induction of chemokines and leukocyte recruitment. Immunity. 1997;6(3):315-25. https://doi. org/10.1016/s1074-7613(00)80334-9.

100. McCutcheon S, Majeska RJ, Spray DC, Schaffler MB, Vazquez M. Apoptotic osteocytes induce RANKL production in bystanders via purinergic signaling and activation of pannexin channels. J Bone Miner Res. 2020. https://doi.org/10.1002/jbmr.3954.

101. Komori T. Cell death in chondrocytes, osteoblasts, and osteocytes. Int J Mol Sci. 2016;17:12. https://doi.org/10.3390/ijms17122045.

102. Al-Dujaili SA, Lau E, Al-Dujaili H, Tsang K, Guenther A, You L. Apoptotic osteocytes regulate osteoclast precursor recruitment and differentiation in vitro. J Cell Biochem. 2011;112(9):2412-23. https://doi. org/10.1002/jcb.23164.
103. Osteocyte-Driven BT, Remodeling B. Calcified Tissue Int. 2014;94(1):2534. https://doi.org/10.1007/s00223-013-9774-y.

104. Algate K, Haynes DR, Bartold PM, Crotti TN, Cantley MD. The effects of tumour necrosis factor-alpha on bone cells involved in periodontal alveolar bone loss; osteoclasts, osteoblasts and osteocytes. J Periodontal Res. 2016;51(5):549-66. https://doi.org/10.1111/jre.12339.

105. Kogianni G, Mann V, Noble BS. Apoptotic bodies convey activity capable of initiating osteoclastogenesis and localized bone destruction. J Bone Min Res. 2008;23(6):915-27. https://doi.org/10.1359/jbmr.080207.

106. Komori T. Functions of the osteocyte network in the regulation of bone mass. Cell Tissue Res. 2013;352(2):191-8. https://doi.org/10.1007/s0044 1-012-1546-x

107. Qiu Q, Zhang F, Wu J, Xu N, Liang M. Gingipains disrupt F-actin and cause osteoblast apoptosis via integrin beta1. J Periodontal Res. 2018;53(5):762-76. https://doi.org/10.1111/jre.12563.

108. Notsu M, Kanazawa I, Takeno A, Tanaka KI, Sugimoto T. Bazedoxifene ameliorates homocysteine-induced apoptosis via NADPH oxidaseinterleukin 1 beta and 6 pathway in osteocyte-like cells. Calcif Tissue Int. 2019;105(4):446-57. https://doi.org/10.1007/s00223-019-00580-7.

109. Delgado-Calle J, Anderson J, Cregor MD, Hiasa M, Chirgwin JM, Carlesso N, et al. Bidirectional notch signaling and osteocyte-derived factors in the bone marrow microenvironment promote tumor cell proliferation and bone destruction in multiple myeloma. Cancer Res. 2016;76(5):1089-100. https://doi.org/10.1158/0008-5472.CAN-15-1703.

110. Kang J, Boonanantanasarn K, Baek K, Woo KM, Ryoo HM, Baek JH, et al. Hyperglycemia increases the expression levels of sclerostin in a reactive oxygen species- and tumor necrosis factor-alpha-dependent manner. J Periodontal Implant Sci. 2015;45(3):101-10. https://doi.org/10.5051/ jpis.2015.45.3.101.

111. Guo C, Yuan L, Wang J-g, Wang F, Yang X-K, Zhang F-h, et al. Lipopolysaccharide (LPS) induces the apoptosis and inhibits osteoblast differentiation through JNK pathway in MC3T3-E1 cells. Inflammation. 2014:37(2):621-31. doi:https://doi.org/10.1007/s10753-013-9778-9.

112. Guo C, Yang X-G, Wang F, Ma X-Y. IL-1a induces apoptosis and inhibits the osteoblast differentiation of MC3T3-E1 cells through the JNK and p38 MAPK pathways. Int J Mol Med. 2016;38(1):319-27. https://doi. org/10.3892/ijmm.2016.2606.

113. Guo C, Wang S-L, Xu S-T, Wang J-G, Song G-H. SP600125 reduces lipopolysaccharide-induced apoptosis and restores the early-stage differentiation of osteoblasts inhibited by LPS through the MAPK pathway in MC3T3-E1 cells. Int J Mol Med. 2015;35(5):1427-34. https://doi. org/10.3892/ijmm.2015.2130.

114. Mori G, Brunetti G, Colucci S, Oranger A, Ciccolella F, Sardone F, et al. Osteoblast apoptosis in periodontal disease: role of TNF-related apoptosis-inducing ligand. Int J Immunopathol Pharmacol. 2009;22(1):95103. https://doi.org/10.1177/039463200902200111.

115. Liccardo D, Cannavo A, Spagnuolo G, Ferrara N, Cittadini A, Rengo C, et al. Periodontal disease: a risk factor for diabetes and cardiovascular disease. Int J Mol Sci. 2019;20:6. https://doi.org/10.3390/ijms20061414.

116. Suh JS, Kim S, Bostrom KI, Wang CY, Kim RH, Park NH. Periodontitisinduced systemic inflammation exacerbates atherosclerosis partly via endothelial-mesenchymal transition in mice. Int J Oral Sci. 2019:11(3):21. https://doi.org/10.1038/s41368-019-0054-1.

117. Fiorillo L, Cervino G, Laino L, D'Amico C, Mauceri R, Tozum TF, et al. Porphyromonas gingivalis, Periodontal and Systemic Implications: A Systematic Review. Dent J (Basel). 2019;7:4. https://doi.org/10.3390/ dj7040114

118. Pizzo G, Guiglia R, Lo Russo L, Campisi G. Dentistry and internal medicine: from the focal infection theory to the periodontal medicine concept. Eur J Intern Med. 2010;21(6):496-502. https://doi.org/10.1016/j. ejim.2010.07.011.

119. Qiao H, Cui Z, Yang S, Ji D, Wang Y, Yang Y, et al. Targeting osteocytes to attenuate early breast cancer bone metastasis by theranostic upconversion nanoparticles with responsive plumbagin release. ACS Nano. 2017;11(7):7259-73. https://doi.org/10.1021/acsnano.7b03197.

120. Chen H, Liu W, Wu X, Gou M, Shen J, Wang H. Advanced glycation end products induced IL-6 and VEGF-A production and apoptosis in osteocyte-like MLO-Y4 cells by activating RAGE and ERK1/2, P38 and STAT3 signalling pathways. Int Immunopharmacol. 2017;52:143-9. https ://doi.org/10.1016/j.intimp.2017.09.004. 
121. Pathak JL, Bakker AD, Luyten FP, Verschueren P, Lems WF, Klein-Nulend J, et al. Systemic inflammation affects human osteocyte-specific protein and cytokine expression. Calcif Tissue Int. 2016;98(6):596-608. https:// doi.org/10.1007/s00223-016-0116-8.

122. Notsu M, Kanazawa I, Takeno A, Yokomoto-Umakoshi M, Tanaka K-I, Yamaguchi T, et al. Advanced glycation end product 3 (AGE3) increases apoptosis and the expression of sclerostin by stimulating TGF- $\beta$ expression and secretion in osteocyte-like MLO-Y4-A2 Cells. Calcified Tissue Int. 2017:100(4):402-11. https://doi.org/10.1007/s00223-017-0243-X.

123. Dussold C, Gerber C, White S, Wang X, Qi L, Francis C, et al. DMP1 prevents osteocyte alterations, FGF23 elevation and left ventricular hypertrophy in mice with chronic kidney disease. Bone Res. 2019;7:12. https://doi.org/10.1038/s41413-019-0051-1.

124. Laster M, Pereira RC, Salusky IB. Unraveling the osteocyte in CKD-MBD post-renal transplantation. Kidney Int. 2019;96(5):1059-61. https://doi. org/10.1016/j.kint.2019.07.021.

125. Gardinier JD, Daly-Seiler CS, Zhang C. Osteocytes' expression of the PTH/PTHrP receptor has differing effects on endocortical and periosteal bone formation during adenine-induced CKD. Bone. 2020;133:115186. https://doi.org/10.1016/j.bone.2019.115186.

126. Ma YV, Lam C, Dalmia S, Gao P, Young J, Middleton K, et al. Mechanical regulation of breast cancer migration and apoptosis via direct and indirect osteocyte signaling. J Cell Biochem. 2018;119(7):5665-75. https ://doi.org/10.1002/jcb.26745.

127. Tu M, Yang M, Yu N, Zhen G, Wan M, Liu W, et al. Inhibition of cyclooxygenase-2 activity in subchondral bone modifies a subtype of osteoarthritis. Bone Res. 2019;7:29. https://doi.org/10.1038/s41413-019-0071-X.

128. Feng JQ, Ward LM, Liu S, Lu Y, Xie Y, Yuan B, et al. Loss of DMP1 causes rickets and osteomalacia and identifies a role for osteocytes in mineral metabolism. Nat Genet. 2006;38(11):1310-5.

129. Liu S, Tang W, Zhou J, Vierthaler L, Quarles LD. Distinct roles for intrinsic osteocyte abnormalities and systemic factors in regulation of FGF23 and bone mineralization in Hyp mice. Am J Physiol Endocrinol Metab. 2007;293(6):E1636-44.

130. Hingorani AD, D'Aiuto F. Chronic inflammation, periodontitis and cardiovascular diseases. Oral Dis. 2008;14(2):102-4. https://doi.org/10.11 11/j.1601-0825.2007.01439.x.

131. Saltiel AR, Olefsky JM. Inflammatory mechanisms linking obesity and metabolic disease. J Clin Invest. 2017;127(1):1-4. https://doi. org/10.1172/JCl92035.

132. Bradshaw EM, Raddassi K, Elyaman W, Orban T, Gottlieb PA, Kent SC, et al. Monocytes from patients with type 1 diabetes spontaneously secrete proinflammatory cytokines inducing Th17 cells. J Immunol. 2009;183(7):4432-9. https://doi.org/10.4049/jimmunol.0900576.

133. Wu Y-Y, Xiao E, Graves DT. Diabetes mellitus related bone metabolism and periodontal disease. Int J Oral Sci. 2015;7(2):63-72. https://doi. org/10.1038/ijos.2015.2.

134. Han YK, Jin Y, Miao YB, Shi T, Lin XP. CD8(+) Foxp3(+) T cells affect alveolar bone homeostasis via modulating Tregs/Th17 during induced periodontitis: an adoptive transfer experiment. Inflammation. 2018;41(5):1791-803. https://doi.org/10.1007/s10753-018-0822-7.

135. Song L, Tan J, Wang Z, Ding P, Tang Q, Xia M, et al. Interleukin-17A facilitates osteoclast differentiation and bone resorption via activation of autophagy in mouse bone marrow macrophages. Mol Med Rep. 2019;19(6):4743-52. https://doi.org/10.3892/mmr.2019.10155.

136. Inanc B, Elcin AE, Elcin YM. Osteogenic induction of human periodontal ligament fibroblasts under two- and three-dimensional culture conditions. Tissue Eng. 2006;12(2):257-66.

137. Kats A, Gerasimcik N, Näreoja T, Nederberg J, Grenlöv S, Lagnöhed E, et al. Aminothiazoles inhibit osteoclastogenesis and PGE production in LPS-stimulated co-cultures of periodontal ligament and RAW 264.7 cells, and RANKL-mediated osteoclastogenesis and bone resorption in
PBMCs. J Cell Mol Med. 2019;23(2):1152-63. https://doi.org/10.1111/ jcmm.14015.

138. Sokos D, Everts V, de Vries TJ. Role of periodontal ligament fibroblasts in osteoclastogenesis: a review. J Periodontal Res. 2015;50(2):152-9. https ://doi.org/10.1111/jre.12197.

139. Yu B, Li Q, Zhou M. LPS-induced upregulation of the TLR4 signaling pathway inhibits osteogenic differentiation of human periodontal ligament stem cells under inflammatory conditions. Int J Mol Med. 2019;43(6):2341-51. https://doi.org/10.3892/ijmm.2019.4165.

140. Zheng J, Chen S, Albiero ML, Vieira GHA, Wang J, Feng JQ, et al. Diabetes activates periodontal ligament fibroblasts via NF-kB In Vivo. J Dent Res. 2018;97(5):580-8. https://doi.org/10.1177/0022034518755697.

141. Yang C-Y, Jeon HH, Alshabab A, Lee YJ, Chung C-H, Graves DT. RANKL deletion in periodontal ligament and bone lining cells blocks orthodontic tooth movement. Int J Oral Sci. 2018;10:1. https://doi. org/10.1038/s41368-017-0004-8.

142. Somerman MJ, Archer SY, Imm GR, Foster RA. A comparative study of human periodontal ligament cells and gingival fibroblasts in vitro. J Dent Res. 1988;67(1):66-70.

143. Mostafa NZ, Uludağ H, Varkey M, Dederich DN, Doschak MR, El-Bialy $\mathrm{TH}$. In vitro osteogenic induction of human gingival fibroblasts for bone regeneration. Open Dent J. 2011;5:139-45. https://doi. org/10.2174/1874210601105010139.

144. de Vries TJ, Schoenmaker T, Wattanaroonwong N, van den Hoonaard M, Nieuwenhuijse A, Beertsen W, et al. Gingival fibroblasts are better at inhibiting osteoclast formation than periodontal ligament fibroblasts. J Cell Biochem. 2006;98(2):370-82.

145. Karlis GD, Schöningh E, Jansen IDC, Schoenmaker T, Hogervorst JMA, van Veen HA, et al. Chronic exposure of gingival fibroblasts to TLR2 or TLR4 agonist inhibits osteoclastogenesis but does not affect osteogenesis. Front Immunol. 2020;11:1693. https://doi.org/10.3389/fimmu .2020.01693.

146. Kandalam U, Kawai T, Ravindran G, Brockman R, Romero J, Munro M, et al. Predifferentiated gingival stem cell-induced bone regeneration in rat alveolar bone defect model. Tissue Eng Part A. 2020. https://doi. org/10.1089/ten.TEA.2020.0052.

147. Nie F, Zhang W, Cui Q, Fu Y, Li H, Zhang J. Kaempferol promotes proliferation and osteogenic differentiation of periodontal ligament stem cells via Wnt/ß-catenin signaling pathway. Life Sci. 2020;258:118143. https://doi.org/10.1016/j.lfs.2020.118143.

148. Shi W, Ling D, Zhang F, Fu X, Lai D, Zhang Y. Curcumin promotes osteogenic differentiation of human periodontal ligament stem cells by inducting EGR1 expression. Arch Oral Biol. 2020;121:104958. https://doi. org/10.1016/j.archoralbio.2020.104958.

149. Carrion JA, Rajani J, Al Bahrawy M, Chan X, Kim TJ, Myneni S, et al. Osteogenic potential of gingival mesenchymal stem cells over titanium machined surfaces. Int J Oral Maxillofac Implants. 2017;32(5):e249-54. https://doi.org/10.11607/jomi.5432.

150. Liu J, Dai Q, Weir MD, Schneider A, Zhang C, Hack GD, et al. Biocompatible nanocomposite enhanced osteogenic and cementogenic differentiation of periodontal ligament stem cells in vitro for periodontal regeneration. Materials (Basel, Switzerland). 2020;13:21. https://doi. org/10.3390/ma13214951.

151. Benjumeda Wijnhoven I, Vallejos R, Santibanez JF, Millán C, Vivanco JF. Analysis of cell-biomaterial interaction through cellular bridge formation in the interface between hGMSCs and CaP bioceramics. Sci Rep UK. 2020;10(1):16493. https://doi.org/10.1038/s41598-020-73428-y.

\section{Publisher's Note}

Springer Nature remains neutral with regard to jurisdictional claims in published maps and institutional affiliations. 